\title{
Simultaneous Measurements of the Vehicle, Track, and Soil Vibrations at a Surface, Bridge, and Tunnel Railway Line
}

\author{
Lutz Auersch \\ Federal Institute of Material Research and Testing (BAM), Unter den Eichen 87, 12200 Berlin, Germany \\ Correspondence should be addressed to Lutz Auersch; lutz.auersch-saworski@bam.de
}

Received 30 January 2017; Revised 31 March 2017; Accepted 7 May 2017; Published 11 June 2017

Academic Editor: Georges Kouroussis

Copyright ( 2017 Lutz Auersch. This is an open access article distributed under the Creative Commons Attribution License, which permits unrestricted use, distribution, and reproduction in any medium, provided the original work is properly cited.

\begin{abstract}
A complex measuring campaign has been performed including the simultaneous measurement of vehicle, track, and soil vibrations during train runs at $16,25,40,63,80,100,125,140$, and $160 \mathrm{~km} / \mathrm{h}$ and impulse measurements of the passenger car, three track sections, and the soil. A ballast track on the soil surface and on a concrete bridge has been investigated as well as a slab track in a tunnel. The evaluation and comparison of all these data show a generally good agreement for all components if the strong low-and high-frequency cut-off characteristics of the layered and damped soil are incorporated. There is a strong causal correlation between the vehicle and the soil by the dynamic excitation forces and a weak relation between the track and the soil by the axle-sequence spectrum of the train. However, the similarity between the axle-impulse spectrum observed at the track and the spectra of the ground vibration leads to the special excitation component of "scattered axle impulses" which is predominant at the far field points of the soil.
\end{abstract}

\section{Introduction}

Trains are passing over tracks, and the irregularities of the wheel and the track yield dynamic loads on the track and the soil. Waves are generated and are propagating through the soil. The ground vibration excites buildings in the vicinity and can annoy persons who live or work inside them. These vibrations due to railway traffic are a theoretical and experimental research field of the Federal Institute of Material Research and Testing (BAM) for 40 years. The most complex measuring campaign has been performed in 1994 at the German high-speed line near Würzburg [1]. Vehicle, track, and soil vibrations have been measured simultaneously at a surface, bridge, and tunnel line (Figure 1). The evaluation of all these measurement data has been published in a German research report [1]. Parts of these experiments have already been published in international journal or conference papers to illustrate special aspects, for example, the ballast and slab track behavior in [2], the ground vibration in [3], the vehicle and track irregularities from the vehicle measurements in [4], the vehicle dynamics in [5], and the bridge dynamics in [6]. This article wants to present the whole set of measuring results to the international community.
Most experimental studies on railway induced ground vibration concentrate on the measurements of the ground vibration, for example, [7-11]. Fortunately, it is now almost a standard to determine the soil properties by wave measurements and analysis; see examples in [12-19]. An important additional information is obtained from measured track irregularities as in [20-24]. Even better are measurements of the vehicle vibration [25-27], namely, axle-box measurements, but they are rarely combined with ground vibration measurements [28].

Sources of the railway induced ground vibration have often been identified by frequencies [7,9] where single peaks have been favored over frequency bands. The vibrations of the track or the near-field ground have previously been treated as the "vibration source" [7, 29]. In the 1980s, force spectra have been introduced as better excitation quantities in US [30] and Germany which are now widely accepted $[20,31-33]$. The excitation forces follow from the vehicle-track interaction. The theoretical vehicle-track-soil models, for example [18, 33], can be checked with the present experimental results for the correct coupling of vehicle, track, and soil or for the necessity of the modelling details. The validations of the author's vehicle-track-soil models are not part of this contribution as 


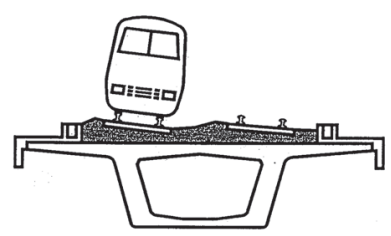

(a)

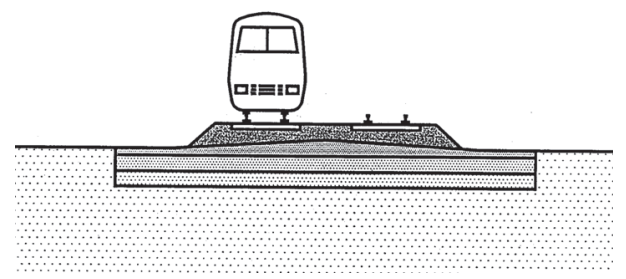

(b)

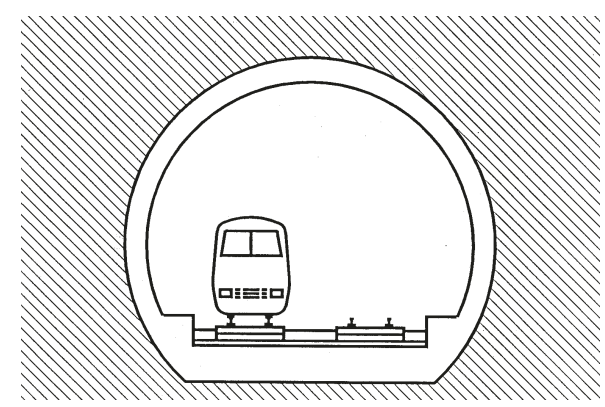

(c)

FIGURE 1: Simultaneous measurements at a surface, bridge, and tunnel line.

they can be found in the literature. Nevertheless, conclusions are drawn exclusively from the experimental results.

The article is structured as follows. The scope of the experimental campaign is exposed in Section 2. In Section 3, the subsystems vehicle, three tracks, the bridge, and the soil are characterized by hammer impact tests. The results due to the runs of the test train are presented for the different elements or measuring points of each subsystem in Section 4. The influence of the train speed is analysed in Section 5. Finally in Section 6, the results of all subsystems are brought together and the excitation of the railway induced ground vibration is discussed.

\section{Methods of the Measuring Campaign}

2.1. Measuring Site and Objects. The simultaneous measurements have been performed in 1994 on a $3 \mathrm{~km}$ long test section of the high-speed line near Würzburg [1]. The test train consisted of a locomotive E113, two carriages (passenger cars Avmz), a measuring car (Bm235), two carriages, and a locomotive E111. The axle load of the measuring car is $100 \mathrm{kN}$; its wheelset mass is $1500 \mathrm{~kg}$. Measurements have been performed simultaneously at three different track situations: a surface line ( $\mathrm{km} \mathrm{300.0),} \mathrm{a} \mathrm{bridge} \mathrm{(} \mathrm{km} 299.7)$, and a tunnel $(\mathrm{km}$ 297.3, Figure 1). The ballast track on the surface and the bridge consists of UIC60 rails and B70 sleepers in $0.6 \mathrm{~m}$ distance. In the tunnel, a slab track with a reinforced concrete plate of $0.3 \mathrm{~m}$ height and integrated rail supports in $0.65 \mathrm{~m}$ distance has been measured.

2.2. Measuring Points. The vibration of the vehicle (the third carriage of the train) has been measured with accelerometers at 12 vertical measuring points (Figure 2). Four accelerometers (A1 to A4) have been mounted on the axle boxes of the first two wheelsets, and 4 accelerometers (B1 to B4) have been mounted at the corresponding points of the first bogie frame. Four accelerometers ( $\mathrm{C} 1$ to $\mathrm{C} 4$ ) have been mounted at the car body above both bogies. All measuring points are chosen symmetrically for the left and right side of the passenger car [34].

The vibrations of the three different tracks have been measured with geophones (velocity transducers) at $3 \times 8$ measuring points. For each track section, 2 rail measuring points and 6 sleeper measuring points have been chosen

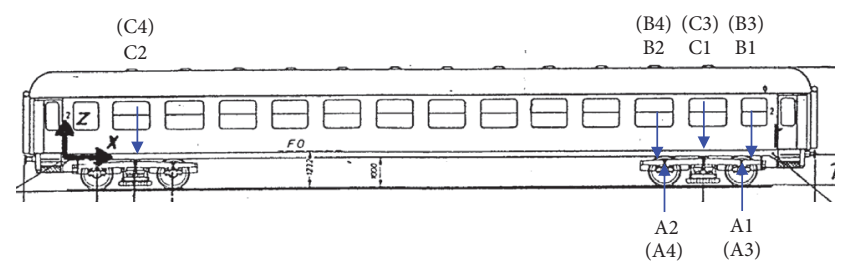

FIGURE 2: Measurement points of the test train (passenger car), axle boxes $\mathrm{A} 1$ and $\mathrm{A} 2$, bogie points $\mathrm{B} 1$ and $\mathrm{B} 2$, and carriage points $\mathrm{C} 1$ and $\mathrm{C} 2$, on the right hand side; $\mathrm{A} 3, \mathrm{~A} 4, \mathrm{~B} 3, \mathrm{~B} 4, \mathrm{C} 3$, and $\mathrm{C} 4$ are located symmetrically on the left hand side.

where one rail point is above the sleeper and the other rail point is between two sleepers. The sleeper points lie at both ends of three consecutive sleepers; see the subfigure in Figure 3. The additional sleeper points can inform about the rail pads, about a possible rocking vibration of the sleeper, and they are a provision if voids are under a measured sleeper.

The vibration of the ground has been measured with 14 geophones in a measuring line up to $100 \mathrm{~m}$ distance from the track; see Figure 3 bottom, and the bridge deck has been measured at 8 points; see Figure 3 top.

2.3. Measuring Equipment. BAM has used geophones (velocity sensors with a $4.5 \mathrm{~Hz}$ eigenfrequency) for all track sections and the soil measurements, while German Railways has used piezo-electric accelerometers in the train [34]. Moreover, an instrumented hammer of $5.4 \mathrm{~kg}$ has been used for the excitation and the force measurements. The measurements at the surface line track section have been recorded using a 72channel measuring system with programmable filters, sample and hold amplifiers, and a 16-bit AD converter running at $2 \mathrm{kHz}$ sampling rate. At the other track sections and in the vehicle, smaller 16-channel measuring systems have been used. All measurements have been evaluated uniquely for a 2 -second time record around the passage of the measuring car over the instrumented track section.

2.4. Measuring Procedures. The test has run on the test section with the following train speeds:

$$
v_{T}=16,25,40,63,80,100,125,140,160 \mathrm{~km} / \mathrm{h} .
$$




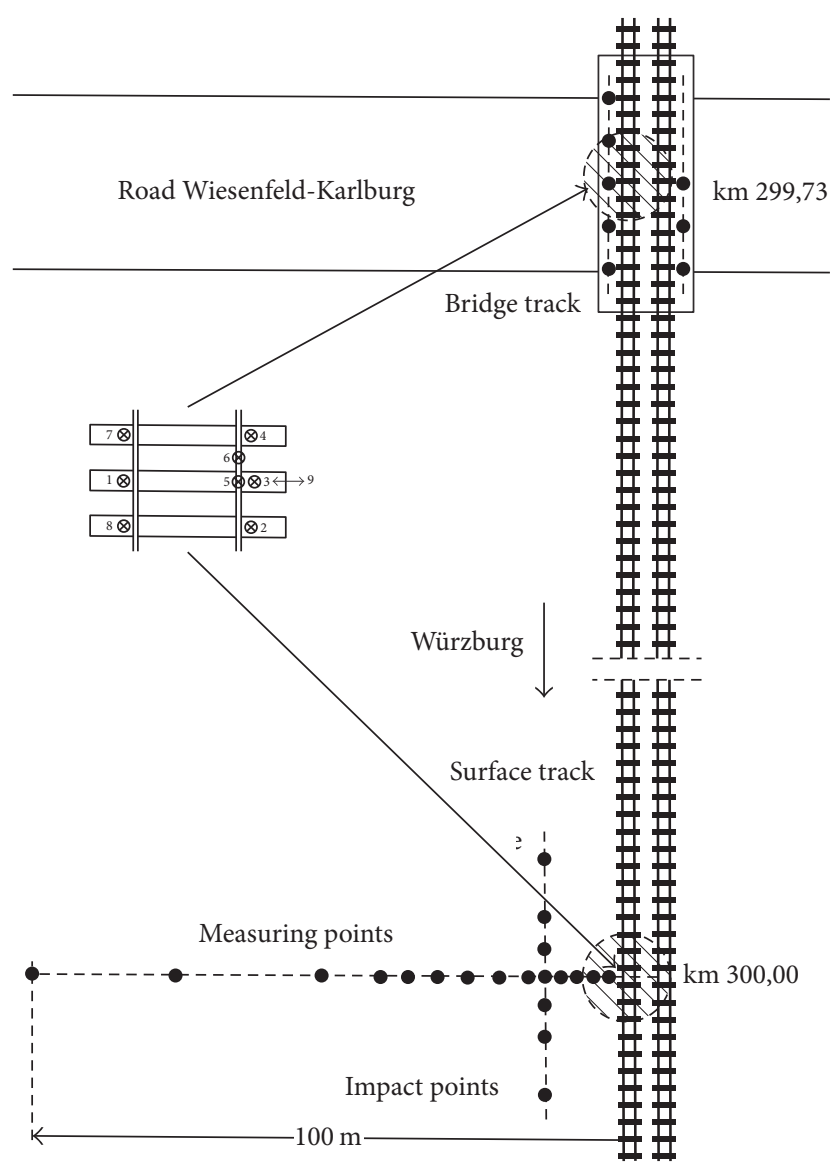

FIGURE 3: Measurement layout at the surface track (track and soil) and the bridge track (track and bridge).

The train speeds are chosen with almost constant differences $v_{T, i+1}-v_{T, I} \approx 20 \mathrm{~Hz}$ for a linear analysis and with constant ratios $v_{T, i+1} / v_{T, I}=\sqrt[3]{ } 2$ for one-third octave band analysis. The latter is shown in this contribution, and the regularly varied train speed facilitates the evaluation and discussion of train speed effects.

In addition to the train passages, each system has been characterized by impulse measurements (hammer impacts), the rigid and flexible modes of the railway vehicle [35], the natural modes of the bridge, the receptance of the three tracks, and the transfer mobility of the soil. It should be respected that the amplitudes from hammer impact are by a factor of ten smaller than the amplitudes from the train passages. Moreover, in case of the hammer impacts, the track is not loaded by the train. It has been shown in [28] for the wave propagation through the soil and in [2] for the receptance of the track that these different types of excitation yielded comparable results.

Finally, it should be explained that the frequency range below $10 \mathrm{~Hz}$ is called the low-frequency range, the frequency range between 10 and $40 \mathrm{~Hz}$ is called the midfrequency range, and the frequencies above $40 \mathrm{~Hz}$ lie in the high-frequency range. It will be seen that the behavior of the different systems in the different frequency ranges is quite diverging.

\section{Results of the Impact Tests for the Characterization of the Subsystems}

3.1. Natural Modes of the Vehicle (Passenger Car). The following elastic modes have been measured for a typical passenger car of the German Railways [35], Figure 4. The first bending mode is at $9 \mathrm{~Hz}$, the lateral bending mode is at $11 \mathrm{~Hz}$, the first torsional mode is at $14 \mathrm{~Hz}$, and the second bending mode is at $18 \mathrm{~Hz}$. Moreover, the rigid body modes of the bogie can be found coupled with the bending modes at $9 \mathrm{~Hz}$ (Figure 4(a)) up to $12 \mathrm{~Hz}$ (without figure). The rigid body modes of the car body have been measured between 1 and $4 \mathrm{~Hz}$ (without figure).

3.2. Receptance Measurements of the Different Tracks. The receptance of the different tracks of the surface, bridge, and tunnel line has been measured by impulse tests. The two ballast tracks have an almost identical superstructure but completely different supporting layers. The slab track has a completely different superstructure which is laid on a gravelsand layer over the natural rock around the tunnel. The receptance functions of these different track "soil" systems are shown in Figure 5 for a wide frequency range and clear differences can be found. The slab track in the tunnel has a high receptance up to $200 \mathrm{~Hz}$ whereas the ballasted tracks drop down below $100 \mathrm{~Hz}$. The bridge and tunnel track show a resonance, whereas the ballasted track on the soil has no resonance amplification. The slab track in the tunnel has two resonances, the strongest at $205 \mathrm{~Hz}$ is due to the rail mass on the rail pad stiffness, and the minor resonance at $120 \mathrm{~Hz}$ is due to the plate mass on the subsoil stiffness. The ballast track on the bridge has a resonance at $50 \mathrm{~Hz}$ where a clear resonance amplification as well as a strong phase drop can be observed.

From the low-frequency amplitudes, it can be concluded that the slab track is somewhat softer due to the soft rail pads, and from the relative phase drops $f_{0} \mathrm{~d} \varphi / \mathrm{d} f$ at the resonance frequency $f_{0}$, it can be concluded that the damping is low for the slab track (because of the soft rail pads), high for the ballast track on the soil, and medium high for the track on the bridge. The receptance of the ballasted tracks is not so different although the surface track lies on a compliant infinite soil and the bridge track on an almost rigid concrete deck. It seems that the ballast layer provides sufficient compliance and damping.

The receptance of the track and the inertia of the wheelset yield the vehicle-track resonance which is the main effect of vehicle-track interaction (see Section 5.1), and the receptance and damping of the track clearly determines the resonance frequency and amplification.

3.3. The Transfer Mobility of the Soil. The site-specific effects are analysed by the transfer functions (transfer mobility) of the soil which have been measured by hammer impacts in the measuring axis, $12 \mathrm{~m}$ away from the track (Figure 6). The soil of this site has a certain cut-on frequency at about $10 \mathrm{~Hz}$ due to a stiff subsoil in $10 \mathrm{~m}$ depth and a certain high cutoff frequency due to the material damping. The strong lowfrequency increase and the strong high-frequency decrease 


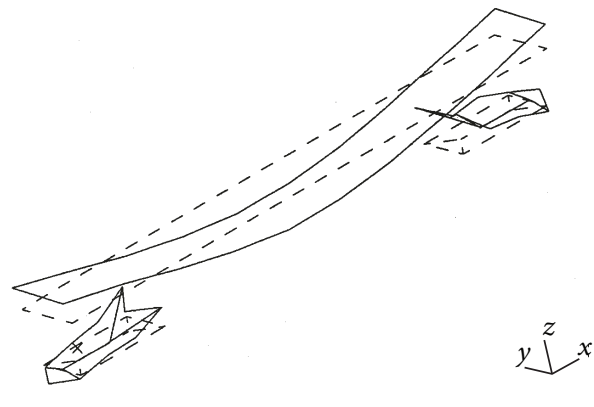

(a)

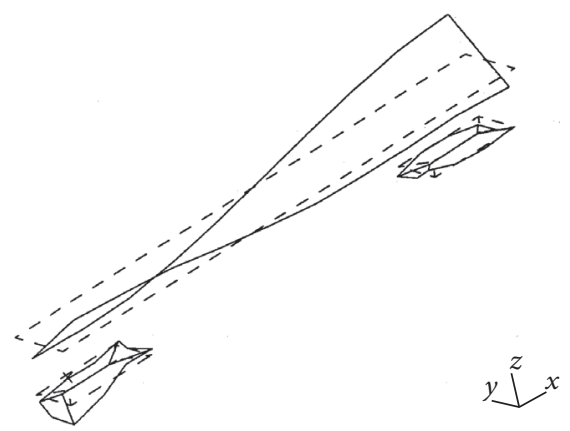

(c)

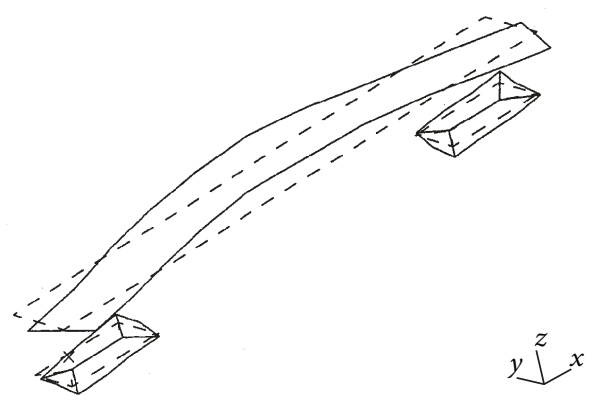

(b)

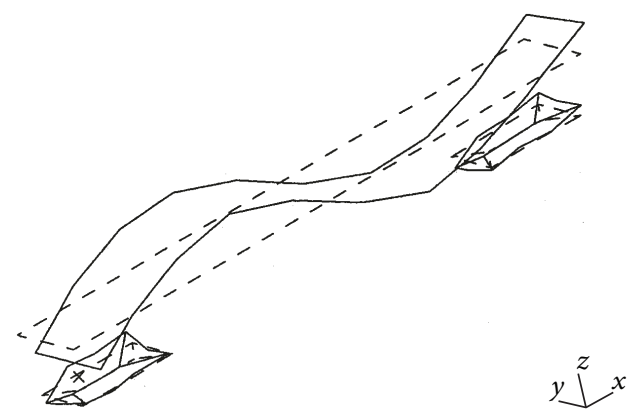

(d)

Figure 4: Natural modes of the car body, (a) first vertical bending at $9 \mathrm{~Hz}$, (b) first lateral bending at $11 \mathrm{~Hz}$, (c) first torsion at $14 \mathrm{~Hz}$, and (d) second vertical bending at $18 \mathrm{~Hz}$.

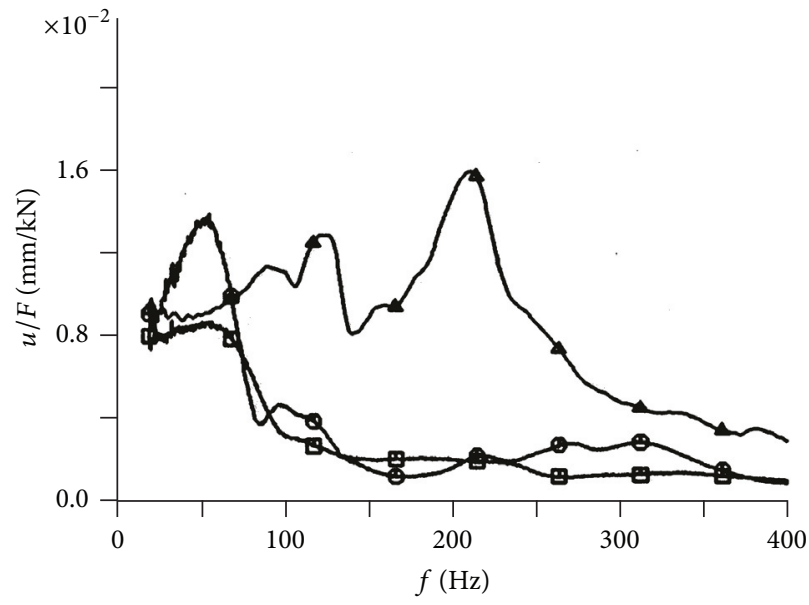

(a)

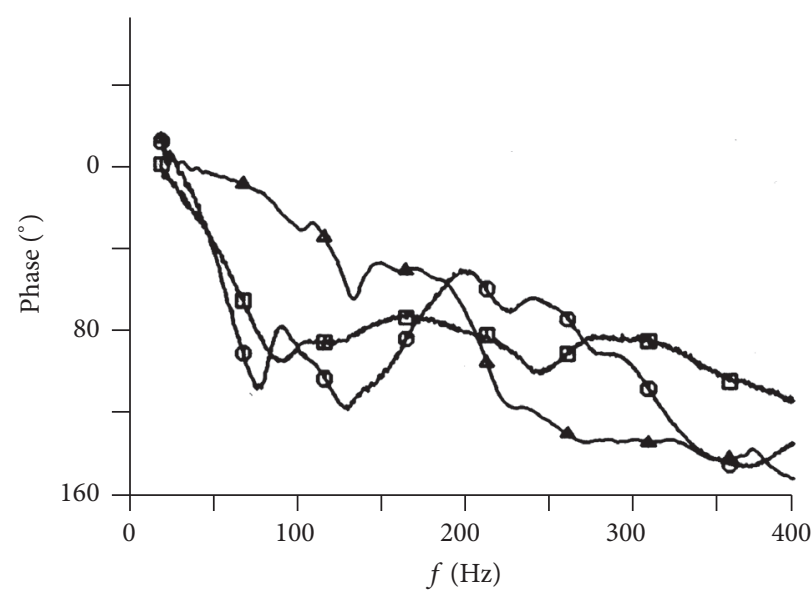

(b)

FIGURE 5: Transfer functions of the tracks of the $\square$ surface, $\bigcirc$ bridge, and $\triangle$ tunnel line and amplitude and phase of the rail receptance above the sleeper.

leave a frequency range of high amplitudes between 10 and $60 \mathrm{~Hz}$. These characteristics will be clearly found at the train induced ground vibration.

The Rayleigh wave velocity of the upper soil has been measured as $270 \mathrm{~m} / \mathrm{s}$ whereas the underlying stiff soil has a wave velocity of about $1000 \mathrm{~m} / \mathrm{s}$. The damping of the upper layer has been determined as $D=4 \%$.

3.4. Natural Modes of the Bridge. A $45 \mathrm{~m}$ long concrete bridge has been measured (Figure 7). The cross section can be seen on Figure 1. The bridge is simply supported on elastic bearings $1 \mathrm{~m}$ away from each end.

A simple modal analysis has been performed using the vibration after the passage of a regular ICE train. The first four natural modes and frequencies are shown in Figure 8. The first bending mode at $f=3.7 \mathrm{~Hz}$ fits perfectly the mode shape of a simply supported bridge. The first torsional mode is at $f=7 \mathrm{~Hz}$. The second (antimetric) modes follow at $f=11 \mathrm{~Hz}$ for the bending vibration and at $f=12.7 \mathrm{~Hz}$ for the torsional vibration. 


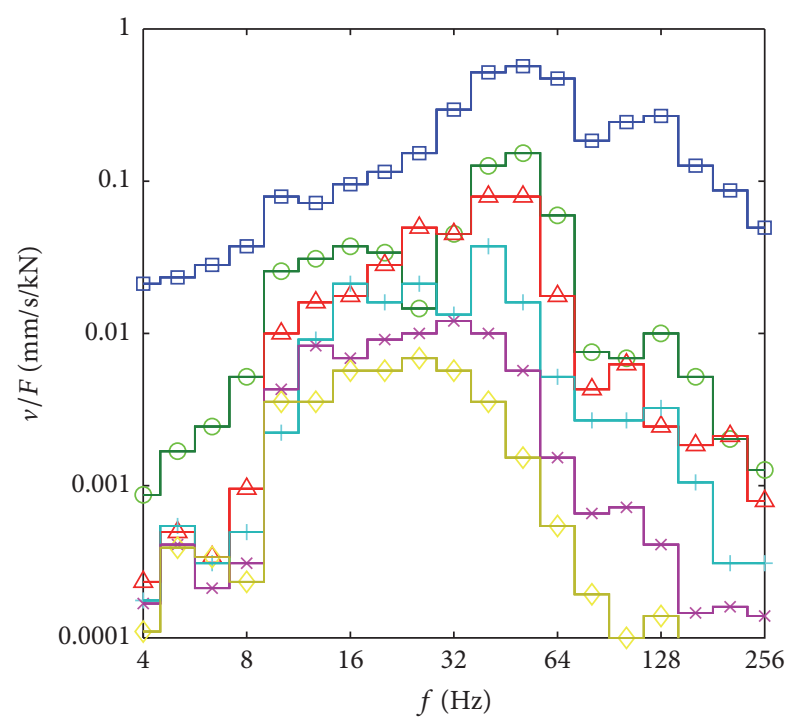

FIGURE 6: Transfer function of the soil and one-third of octave band spectra of the mobility at the distances $\square 2.5, \bigcirc 7.5, \triangle 12.5,+22.5, \times$ 37.5 , and $\diamond 62.5 \mathrm{~m}$.

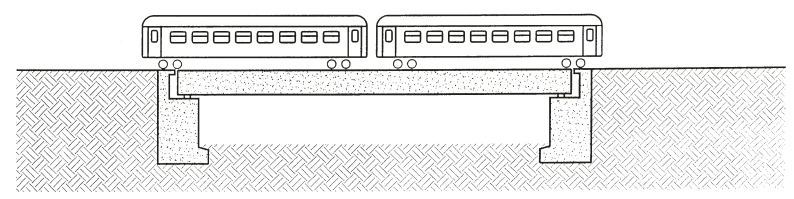

FIGURE 7: $45 \mathrm{~m}$ long concrete railway bridge excited by the passage of the train.

\section{Vehicle, Track, and Soil Vibrations due to Train Passages}

4.1. The Vibration Amplitudes of the Different Vehicle Components. The vibrations of the vehicle during a test run with $160 \mathrm{~km} / \mathrm{h}$ have been analysed by one-third octave band spectra. The vibrations of the car body, the bogie, and the wheelset are completely different due to the primary and secondary suspension (Figure 9(a)). As the car body is isolated from the track irregularities by the soft secondary suspension, all car-body amplitudes above $4 \mathrm{~Hz}$ are very low compared to the other components. The reduction is at least $1: 10$, for frequencies higher than $16 \mathrm{~Hz}$ even $1: 30$ (after the cut-off frequency of the primary suspension). The wheelset has its highest amplitudes at the high frequencies between 64 and $128 \mathrm{~Hz}$ up to an acceleration of $5 \mathrm{~m} / \mathrm{s}^{2}$ $(0.5 \mathrm{~g})$. At lower frequencies, the wheelset and the bogie have approximately the same amplitudes; the bogie has somewhat higher amplitudes at 5 to $12 \mathrm{~Hz}$ where its rigid body modes are situated.

4.2. The Passage of the Measuring Car over Three Different Track Situations. The vibration amplitudes of the different tracks due to the passage of the measuring car with $160 \mathrm{~km} / \mathrm{h}$ are presented in Figures 9(b)-9(d). In general, the rail spectra look very similar for all track types. They are more or less constant over the whole frequency range. Compared to the rail, the sleeper and plate amplitudes of the slab track are much lower by a factor of about 10 . The subsoil point of the ballast track (Figure 9(b)) has also much lower amplitudes. The third-span point of the bridge (Figure $9(c)$ ) is lower for the high frequencies but comparable in the midfrequency range. At $10 \mathrm{~Hz}$ the bridge deck vibrates even stronger than the track which indicates a resonance of the bridge structure. Small differences between the rail and the sleepers can be found for the ballast tracks (Figures 9(b) and 9(c)) which could be quantified as a factor of 1.5. Similar factors between rail and sleeper of 1.5 for the ballast and 10 for the slab track have also been observed for the impact tests of the track.

4.3. Ground Vibrations due to the Passage of the Train. The characteristics of the vibrations at different measuring points are demonstrated in Figure 10 for the passage of four bogies with a speed of $160 \mathrm{~km} / \mathrm{h}$. At the rail (or sleeper, Figure 10(a)), the passage of every axle can be observed clearly. At $2 \mathrm{~m}$ distance from the track (Figure 10(b)), the axle impulses can still be traced back, but they are completely lost at $10 \mathrm{~m}$ distance at the latest (Figure 10(c)). A stationary vibration of many frequencies can be found there as in most measuring points of the midfield. The far field ( $r=100 \mathrm{~m}$, Figure $10(\mathrm{~d})$ ) is still stationary, but only with a narrow frequency band (around $12 \mathrm{~Hz}$ for this specific site).

Figures 11(a)-11(e) show the third of octave band spectra of the ground vibration during the passage of the locomotive. The spectra of the soil vibration show typical frequencies and frequency ranges of railway excitation. Maxima can be found at 32,40 , and $50 \mathrm{~Hz}$ for 60,80 , and $100 \mathrm{~km} / \mathrm{h}$ which are due to the sleeper-distance excitation $[3,36]$. This component is further analysed by linear spectra in Appendix. At the nearfield point, the low-frequency spectrum is due to the passage of the static axle loads. There is another important frequency range at $12-16 \mathrm{~Hz}$ which is rather fixed for all train speeds. In general, the whole ground vibrations are rather constantly concentrated between 10 and $60 \mathrm{~Hz}$, independent of the train speed. This could be explained by the filter effects of the soil with a certain cut-on frequency due to a stiff subsoil and a certain cut-off frequency due to the material damping. The train induced ground vibrations are very similar to the hammer induced transfer functions of the soil (Figure 6). The attenuation with distance is strongest at the high frequencies where a reduction of two decades is typical at $100 \mathrm{~Hz}$ and for a distance of $50 \mathrm{~m}$. At low frequencies, the quasi-static response is abruptly reduced from $2.5 \mathrm{~m}$ to $5 \mathrm{~m}$ distance. The weakest attenuation can be found at 10 to $16 \mathrm{~Hz}$ and half a decade for $50 \mathrm{~m}$ or even less. These different attenuation laws lead to the dominating midfrequency component at the far field.

The passage of carriages is analysed in Figures 11(f)-11(j). The characteristics are generally the same as for the locomotive. The dynamic components "sleeper-distance" and "soil" are much clearer for the locomotive, so it could be concluded that these components depend on the static axle loads.

\section{Influence of the Train Speed}

5.1. Acceleration of the Vehicle Components. The car body (Figure 12(a)) has low amplitudes which increase with the 


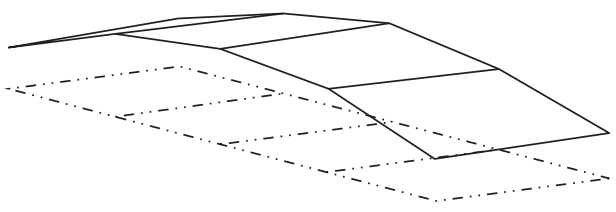

(a)

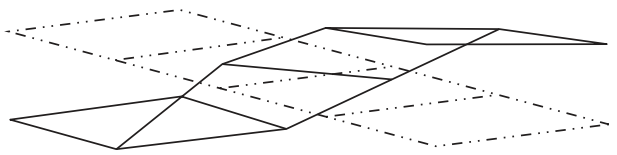

(c)

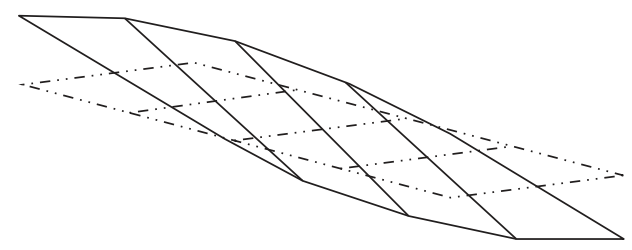

(b)

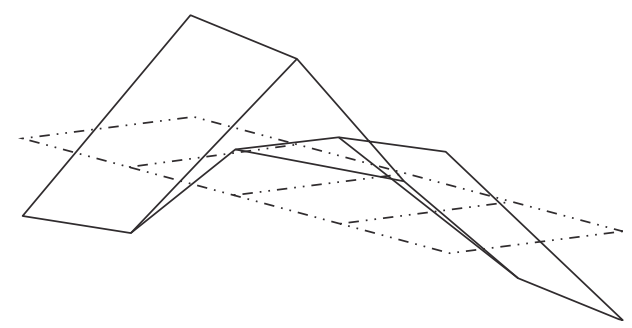

(d)

FIGURE 8: Natural modes of the bridge, (a) first bending at $3.7 \mathrm{~Hz}$, (b) first torsion at $7 \mathrm{~Hz}$, (c) second bending at $11 \mathrm{~Hz}$, and (d) second torsion at $12.7 \mathrm{~Hz}$. (Note that the almost zero amplitudes at the support points at the end of the bridge have not been measured and are not included in the figures.)

train speed while the shape of the spectra remains constant. There is a typical decrease with frequency at $20 \mathrm{~Hz}$ presumably due to the primary suspension. The bogie (Figure 12(b)) shows a similar increase with train speed mainly at low frequencies. A typical frequency range of $5-8 \mathrm{~Hz}$ for $125 \mathrm{~km} / \mathrm{h}$ and of $6-10 \mathrm{~Hz}$ for $160 \mathrm{~km} / \mathrm{h}$, respectively, is clearly shifted with the train speed.

The acceleration of the wheelset is analysed in more detail in Figures 12(c)-12(f) where the third of octave band spectra are presented for all four wheels of a bogie. The low-frequency and midfrequency spectra are almost identical which demonstrates the good quality of the measurements. Moreover, the long wavelength excitation (longer than the perimeter of the wheel) at low and midfrequencies is due to the track irregularities (track alignment errors). The most important part lies between 6 and $10 \mathrm{~Hz}$ for $160 \mathrm{~km} / \mathrm{h}$ and is shifted to lower frequencies for lower train speeds. This is in agreement with the results of the bogie (Figure 12(b)). An additional component can be found especially at the wheelset and the first and second out-of-roundness of the wheel at 16 and $32 \mathrm{~Hz}$ for $160 \mathrm{~km} / \mathrm{h}$ [4]. As the out-ofroundness is different for each of the four wheels, the corresponding amplitudes vary in Figures 12(c)-12(f). The frequency shift of these peaks with the train speed can be clearly observed. A specific component, a maximum shifted from 32 to $40,50,64$, and $80 \mathrm{~Hz}$, can be clearly found in Figures $12(\mathrm{e})-12(\mathrm{~g})$. This is the component due to the passage over equally spaced sleepers (sleeper-distance excitation) [3]. All these low-frequency and midfrequency acceleration amplitudes increase with the train speed as $a \sim v_{T}{ }^{2}$ and that means that the displacements of the wheels are speed independent in this frequency range and represent directly the track and vehicle irregularities. At high frequencies above $64 \mathrm{~Hz}$, the irregularities are dominated by the wheel outof-roundness of higher order. This can be concluded from narrow band spectra [4] and from the different spectra for each single wheel. In general, the high-frequency amplitudes of the wheels are higher but not so increasing for increasing train speeds. This is due to the fact that the vehicle-trackresonance, which can most clearly be seen for the slab track at $64 \mathrm{~Hz}$ (Figure 12(h)), is passed in this frequency range. The frequency of highest amplitudes is constantly $64 \mathrm{~Hz}$ for all train speeds, and these amplitudes are the highest for all wheelset measurements. The corresponding resonance for the ballast track can be assumed at 80 or $100 \mathrm{~Hz}$. Flexible wheelset modes (Figure 13) lie in the same frequency range and would yield coupled wheelset-track modes which would explain the wider resonance region. The slab track has only little damping due to the soft rail pads so that the vehicle-track resonance has a high amplification. The smaller damping of the slab track yields also a reduction for frequencies above the vehicle-track resonance which is a clearly stronger reduction than for the ballast track. The low-frequency components due to the track irregularities (without the first wheel out-ofroundness at $16 \mathrm{~Hz}$ for $160 \mathrm{~km} / \mathrm{h}$ ) are smaller for the ballast track on the bridge and the slab track in the tunnel. This reflects quite probably the better track quality of these track types.

5.2. The Passage over the Different Tracks with Different Train Speeds. The track spectra for all train speeds are presented in Figures 14(a)-14(c) for all three track situations. The lowfrequency spectra are very similar. The differences between the track types can be found at frequencies higher than $32 \mathrm{~Hz}$. The ballast track on the soil has the lowest amplitudes. The bridge track has higher almost constant high-frequency amplitudes, whereas the slab track in the tunnel shows a maximum around $64 \mathrm{~Hz}$ for all train speeds. The amplitudes increase with train speed most regularly at the bridge track.

The low- and midfrequency spectra of the track vibration show a regular pattern which is shifted with train speed. There is a typical amplified region between 12 and $20 \mathrm{~Hz}$ for 


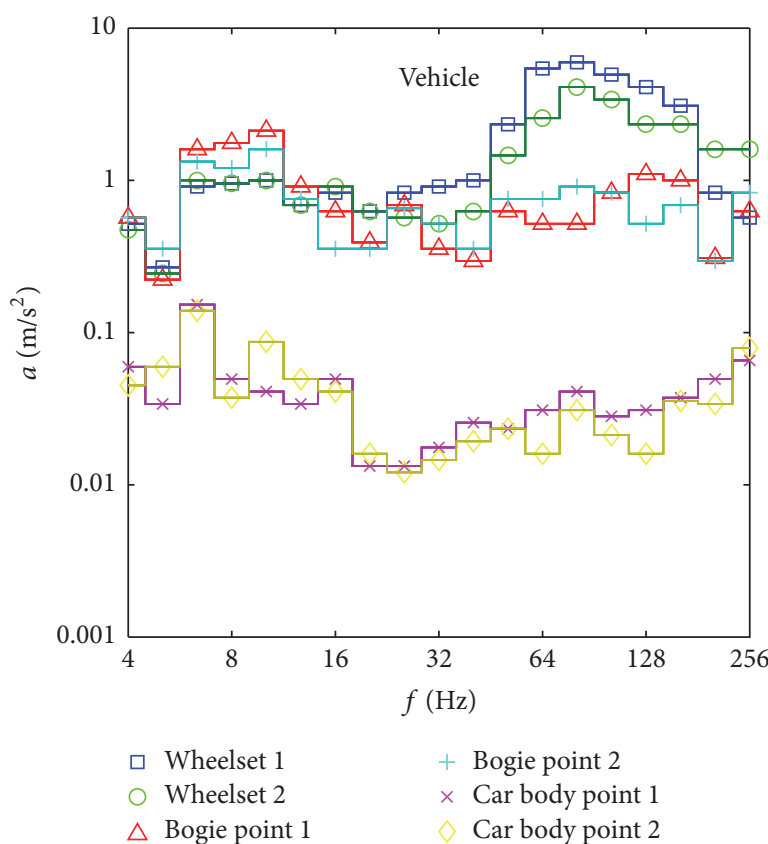

(a)

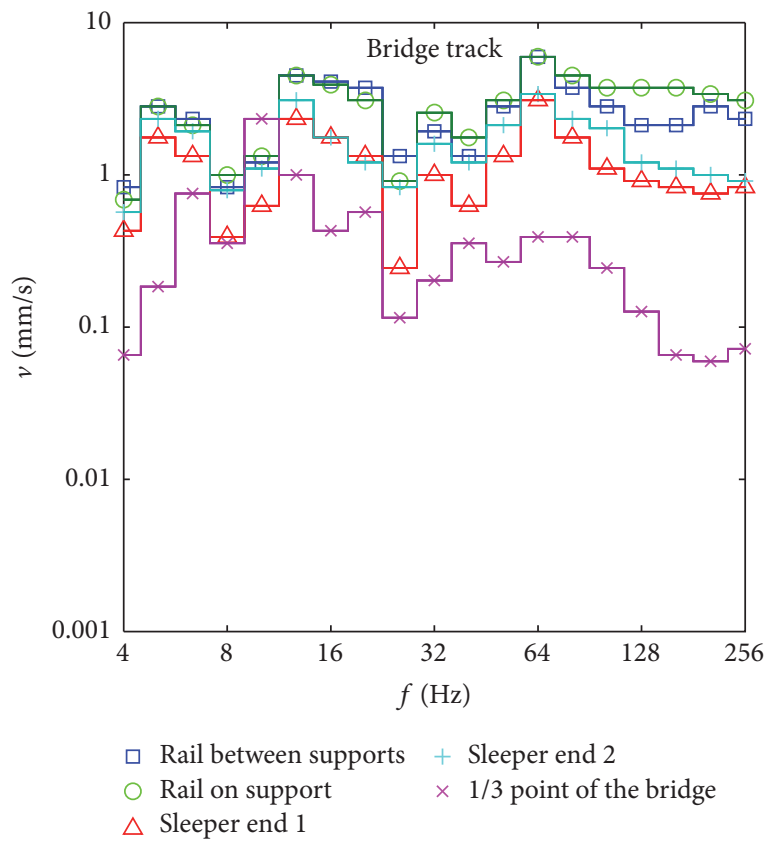

(c)

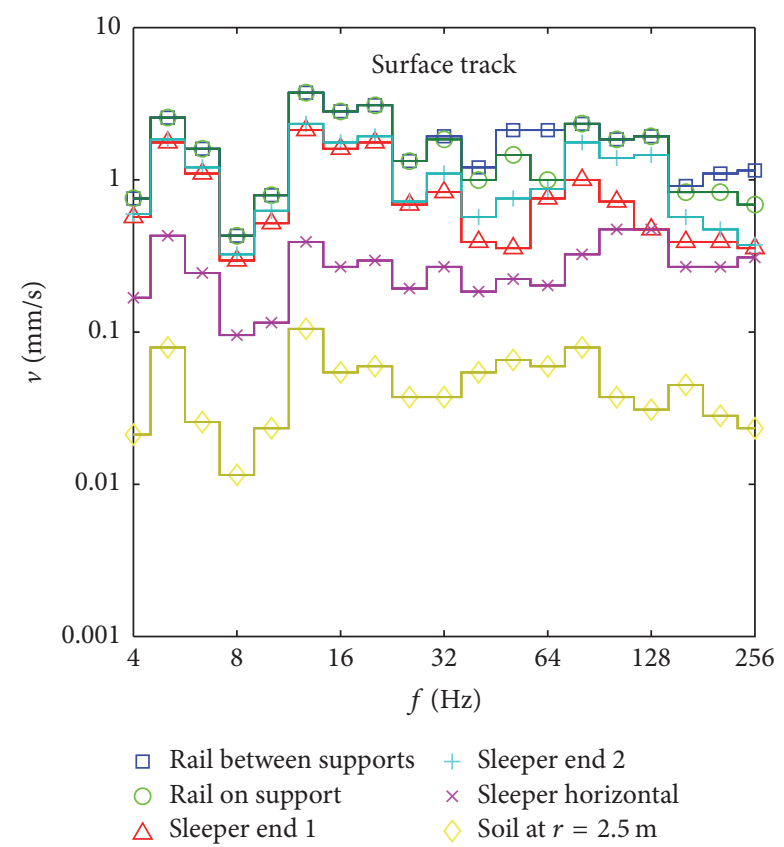

(b)

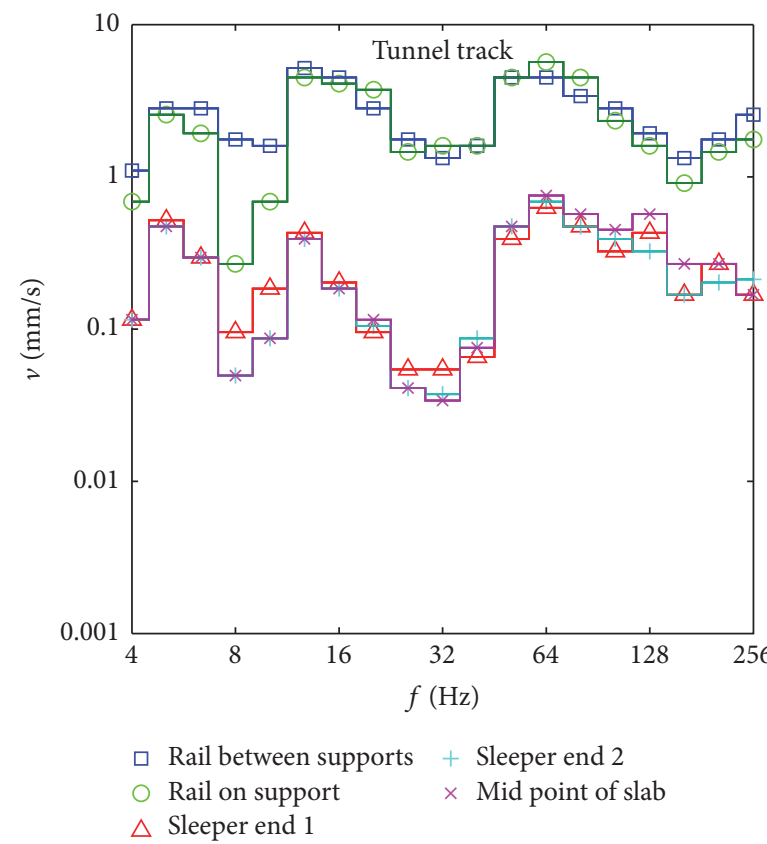

(d)

FIGURE 9: Vibrations of the railway vehicle (a) and the tracks of the surface line (b), the bridge line (c), and the tunnel line (d) due to the passage of the measuring car with $v_{T}=160 \mathrm{~km} / \mathrm{h}$; one-third octave band spectra.

$160 \mathrm{~km} / \mathrm{h}$, a strong minimum at $10 \mathrm{~Hz}$, and a second minimum at $25 \mathrm{~Hz}$. This frequency range includes the dynamic response to track irregularities and the response to the passage of the static loads. Both excitations are repeated for each axle of the train and their frequency content is therefore modified by the axle-sequence spectrum of the train $[3,36]$. The two minima of the measured spectra are caused by the distance between the two axles of a bogie of $2.5 \mathrm{~m}$. The corresponding first minimum is strong whereas the theoretical minimum is weak for the second frequency of $25 \mathrm{~Hz}$ (for $160 \mathrm{~km} / \mathrm{h}$ ). The measured second minimum, however, is stronger and wider (sometimes including threethirds of octaves, up to $40 \mathrm{~Hz}$ for $160 \mathrm{~km} / \mathrm{h}$ at the tunnel track) and the amplitudes after this minimum are smaller than the amplitudes before this minimum. This can be explained by the band-limited spectrum of the axle impulse which also drops down in this frequency range. The two characteristic spectra of axle impulse and axle sequence can only be seen for 


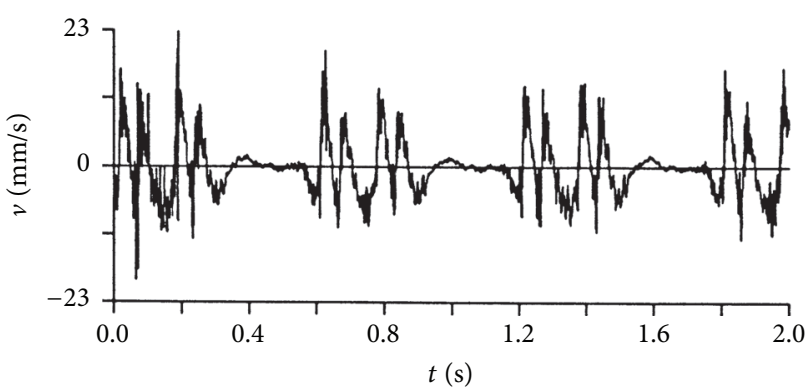

(a)

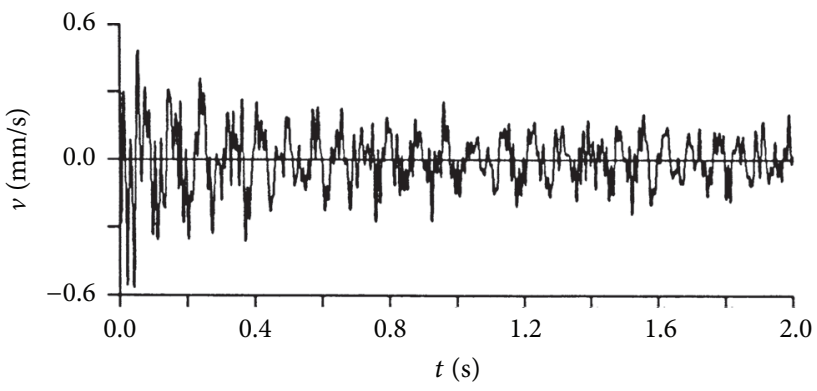

(c)

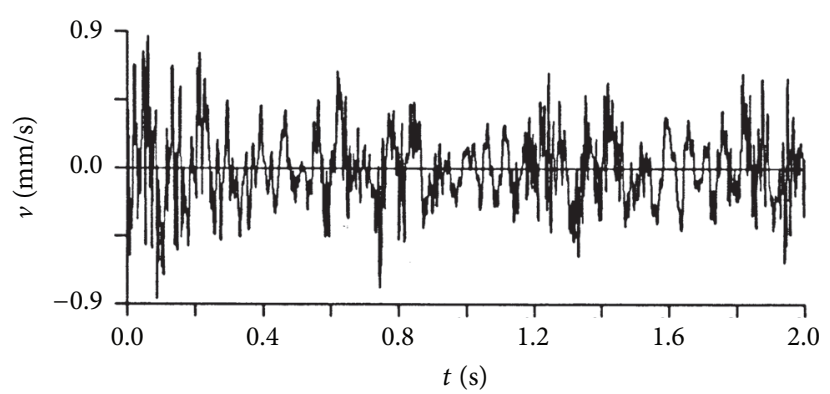

(b)

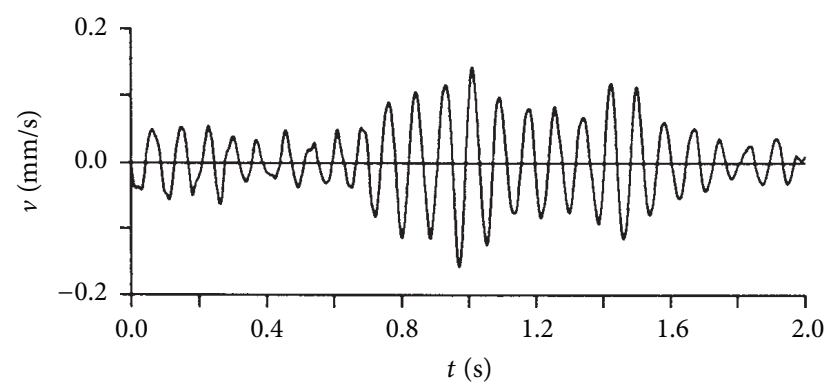

(d)

FIGURE 10: Vibrations of the railway track and the soil during the passage of the measuring car with $v_{T}=160 \mathrm{~km} / \mathrm{h}$ and time records of the particle velocities (a) at the rail, (b) at $2.5 \mathrm{~m},(\mathrm{c})$ at $10 \mathrm{~m}$, and (d) at $100 \mathrm{~m}$ distance from the track.

a fixed observer at the track or the soil, but not by a moving observer in the train. The subsystems vehicle and track have completely different characteristics of vibrations where the static loads are dominant as impulses at the track whereas the static loads are not visible at the vehicle vibrations.

5.3. Excitation of Bridge Resonances. The response of the bridge to the passage of the test train is quite different for different train speeds. The time records for 100 and $160 \mathrm{~km} / \mathrm{h}$ display a dominating vibration with two different frequencies, $7 \mathrm{~Hz}$ for $100 \mathrm{~km} / \mathrm{h}$ and $11 \mathrm{~Hz}$ for $160 \mathrm{~km} / \mathrm{h}$ (Figure 15). This different behavior can be explained by the axle-sequence spectrum of the train. For $100 \mathrm{~km} / \mathrm{h}$, the axle-sequence spectrum has a (weak) maximum at $7 \mathrm{~Hz}$ and a (the second) minimum at $11 \mathrm{~Hz}$. On the other hand for $160 \mathrm{~km} / \mathrm{h}$, the axlesequence spectrum has a strong minimum at $7 \mathrm{~Hz}$ and a weak maximum at $11 \mathrm{~Hz}$. So, the excitation by static loads, the entering and leaving of the bridge, or dynamic loads due to track irregularities, is reduced at the one natural frequency and amplified at the other natural frequency leading to the almost monofrequent bridge responses in Figure 15.

5.4. Ground Vibration for Different Train Speeds. The influence of the train speed on the ground vibration is presented for five different distances to the track in Figure 11. For all distances, a clear increase of the velocity amplitudes with the train speed is observed. Specific excitation frequencies that are shifted with train speed can hardly be found. A peak at $5 \mathrm{~Hz}$ (for $160 \mathrm{~km} / \mathrm{h}$ ) which is due to the static load and the axle-sequence spectrum is included in the near field at $2.5 \mathrm{~m}$. A maximum constantly at $12 \mathrm{~Hz}$ becomes dominant at all far field points. The amplitudes at frequencies below this characteristic frequency of $12 \mathrm{~Hz}$ are very small. Also on the other end, the amplitudes for frequencies higher than $80 \mathrm{~Hz}$ are strongly reduced. They are present only at the nearfield point close to the track. At the track (Figure 14(a)) and at $2.5 \mathrm{~m}$ distance (Figure 16(a)), the mid- and the highfrequency parts are of similar amplitude, and the passage of the static loads is present. The static load effect disappears at $5 \mathrm{~m}$ distance (Figure 16(b)), and the high-frequency part is stronger. The high-frequency part is continuously reduced with further distances from the track. At $17.5 \mathrm{~m}$, mid- and high-frequency parts are in balance, whereas the midfrequency part is already dominant at $30 \mathrm{~m}$. Finally at $100 \mathrm{~m}$ distance, the high-frequency part has vanished and the midfrequency part at $12 \mathrm{~Hz}$ has been left over. By these strong filter effects of the soil, the railway induced ground vibration at this site are a frequency band from 10 to $64 \mathrm{~Hz}$. The characteristics of the soil are stronger than the characteristics of the train, and some train specific components are filtered out by the soil.

As a special effect, the amplitudes at $12 \mathrm{~Hz}$ strongly increase for the train speeds of 125 and $160 \mathrm{~km} / \mathrm{h}$. This could be due to the fact that the amplified frequencies of the axlesequence spectrum reach the layer frequency of the soil for these train speeds. For lower train speeds, the main part of the axle-sequence spectrum is hidden in the low-frequency cutoff range. They would be better visible if the layer frequency would be lower than the typical axle-sequence range.

In Figure 16(f), the ground vibration above the tunnel track is presented and can be compared with Figure 16(c) for the surface line. The amplitudes for both tracks are almost the same for the high frequencies, but quite different at low frequencies. For frequencies between 8 and $25 \mathrm{~Hz}$, the ground 


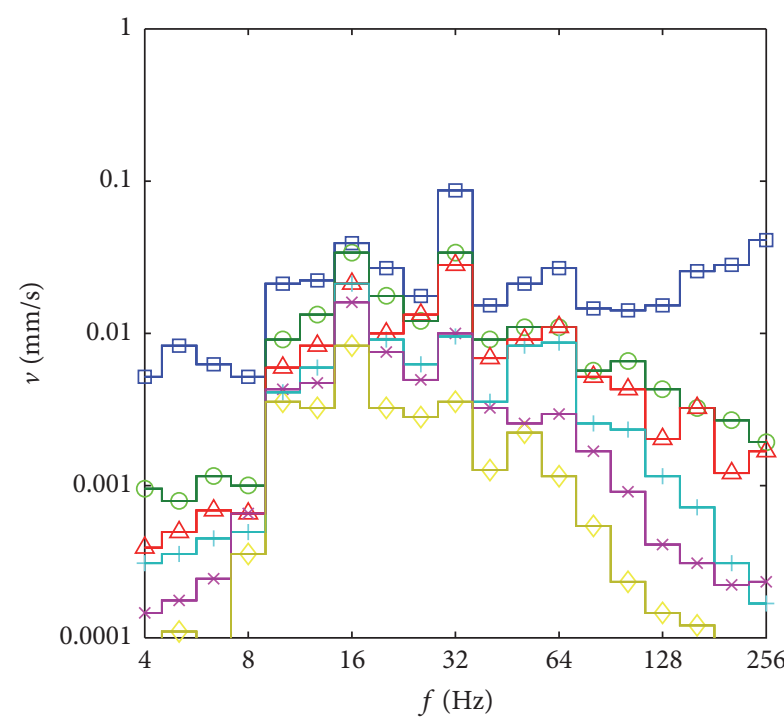

(a)

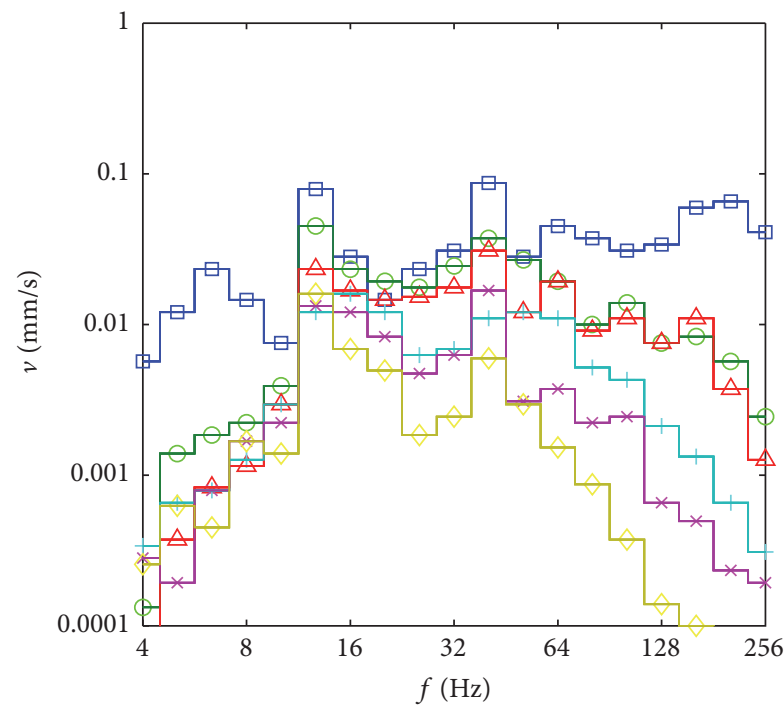

(b)

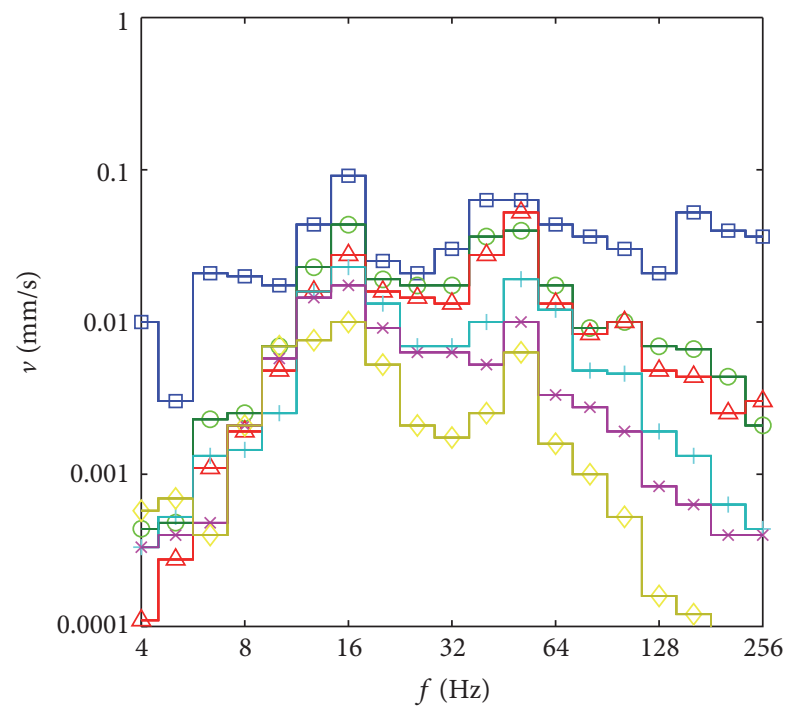

(c)

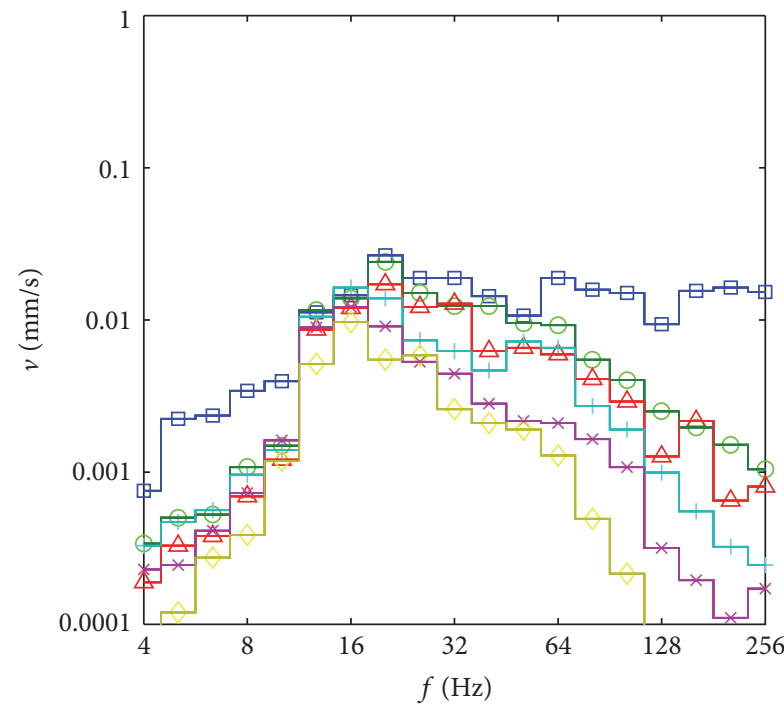

(f)

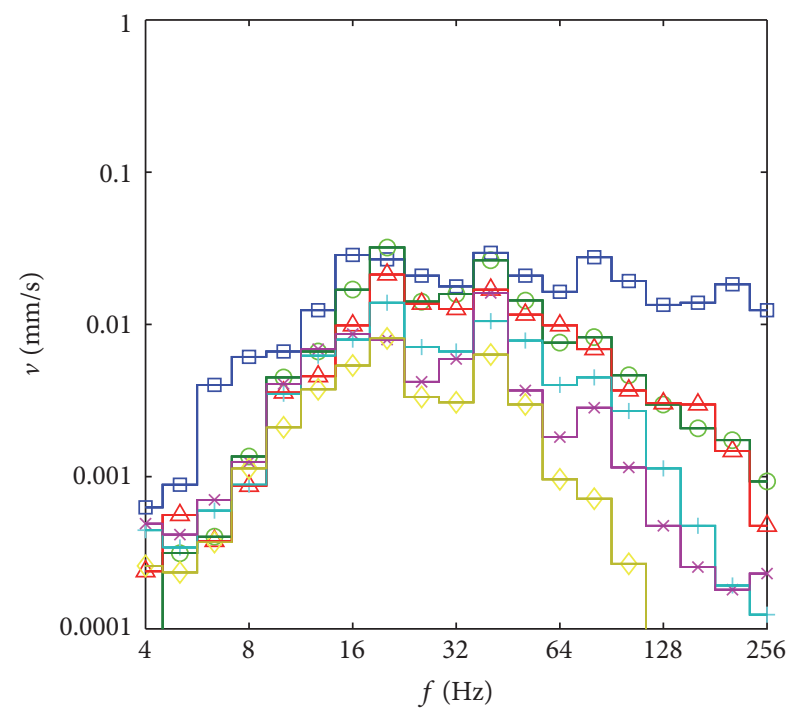

(g)

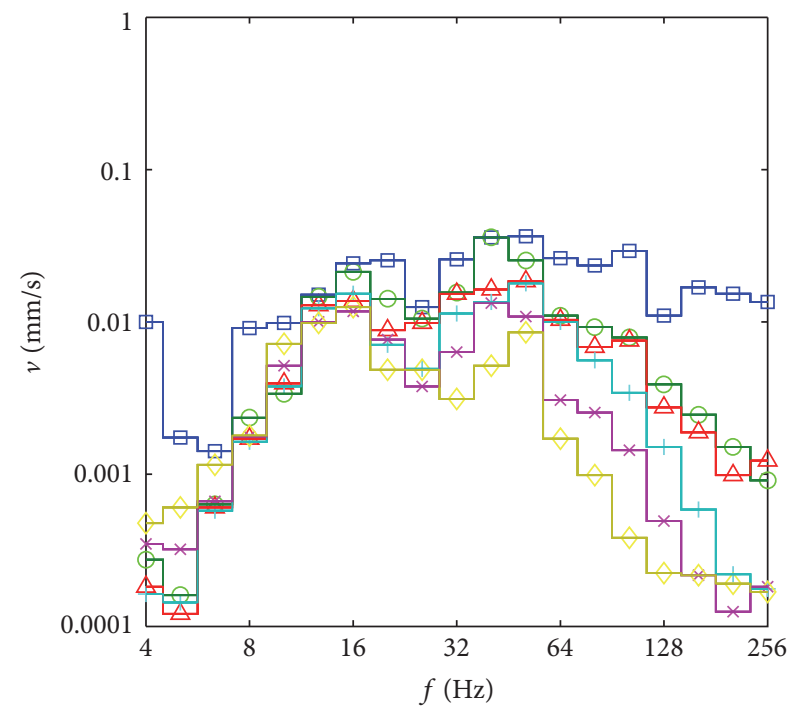

(h)

FIGURE 11: Continued. 


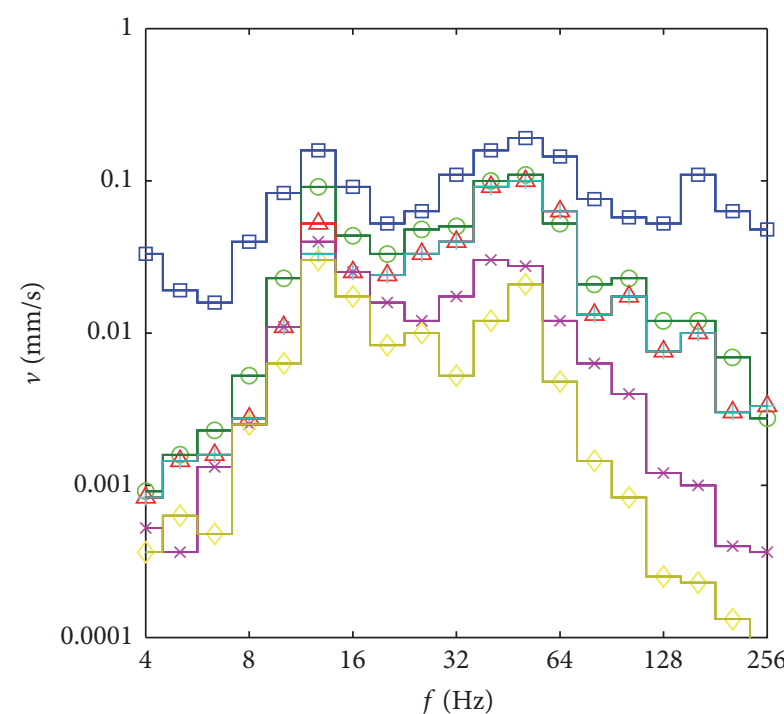

(d)

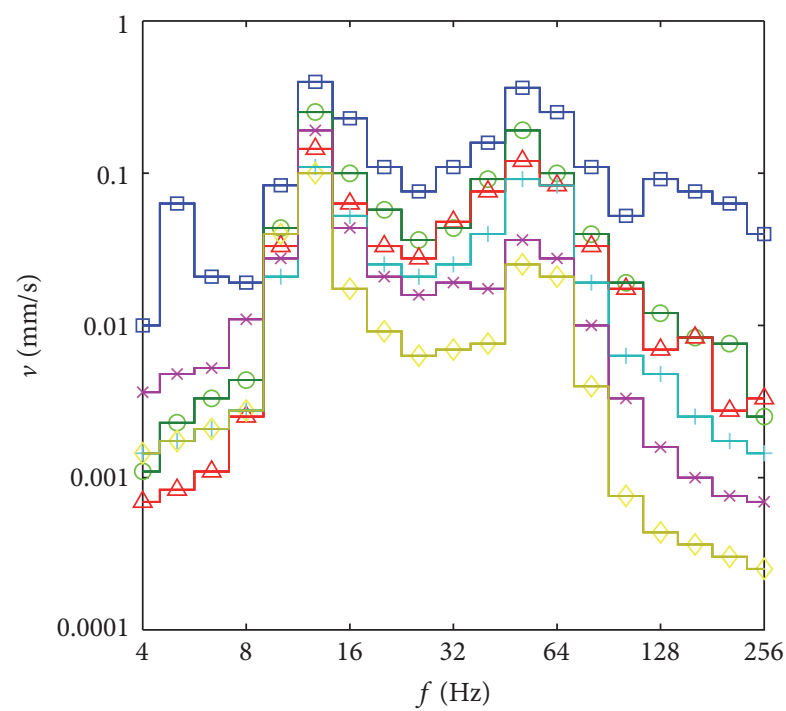

(e)

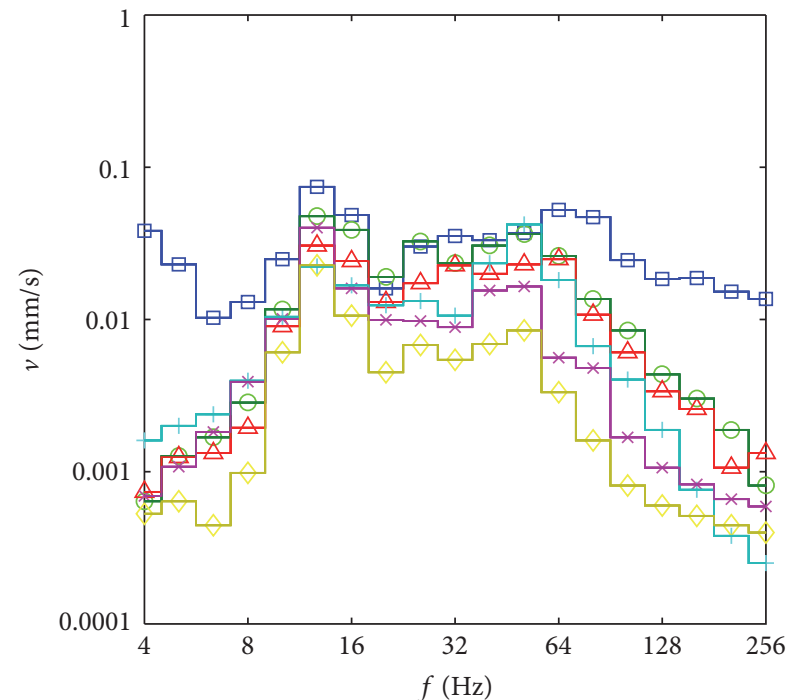

(i)

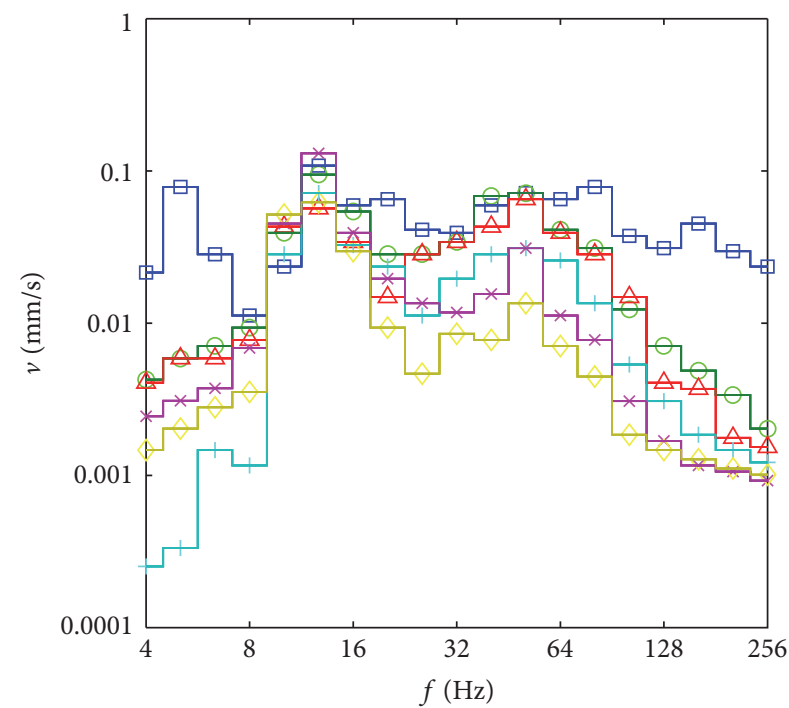

(j)

FIGURE 11: Vibration of the soil (one-third octave band spectra) at distances $\square 2.5, \bigcirc 7.5, \triangle 12.5,+20, \times 30$, and $\diamond 50 \mathrm{~m}$, due to train passages with different speeds (a, f) $63 \mathrm{~km} / \mathrm{h},(\mathrm{b}, \mathrm{g}) 80 \mathrm{~km} / \mathrm{h},(\mathrm{c}, \mathrm{h}) 100 \mathrm{~km} / \mathrm{h},(\mathrm{d}, \mathrm{i}) 125 \mathrm{~km} / \mathrm{h}$, and (e, j) $160 \mathrm{~km} / \mathrm{h}$; locomotive (a, b, c, d, e) and measuring $\operatorname{car}(f, g, h, i, j)$.

vibration amplitudes of the ballast tracks are up to a factor of 10 higher than the amplitudes of the slab track. This can be explained by the lower track irregularities due to the better track quality of the slab track.

\section{Discussion of Excitation and Amplification Mechanisms}

6.1. The Low-, Mid-, and High-Frequency Excitation Components. Now, the results of the different subsystems are brought together. There are three frequency ranges which could be distinguished, a low-frequency range from 0 to $10 \mathrm{~Hz}$, a midfrequency range from 10 to $40 \mathrm{~Hz}$, and a highfrequency range from 40 to $100 \mathrm{~Hz}$.
The low-frequency range is due to the passage of the static load. This part is only relevant at the track and the close near-field soil. At the vehicle and at the mid- and far field soil, the static load has no (dynamic) effect. It yields only static displacements and forces at zero frequency and ground vibration whose frequency band is drastically reduced with the distance to the track. The most important parts of the vibration are the midfrequency part in the range of 10 to $40 \mathrm{~Hz}$ and the high-frequency part of 40 to $100 \mathrm{~Hz}$.

The midfrequency range, especially the range between 10 and $16 \mathrm{~Hz}$, is strong at the track and at the soil, and it becomes dominant at the far field of the soil. The vehicle vibration includes also low-frequency and midfrequency components. The vibrations are due to track alignment errors and the 


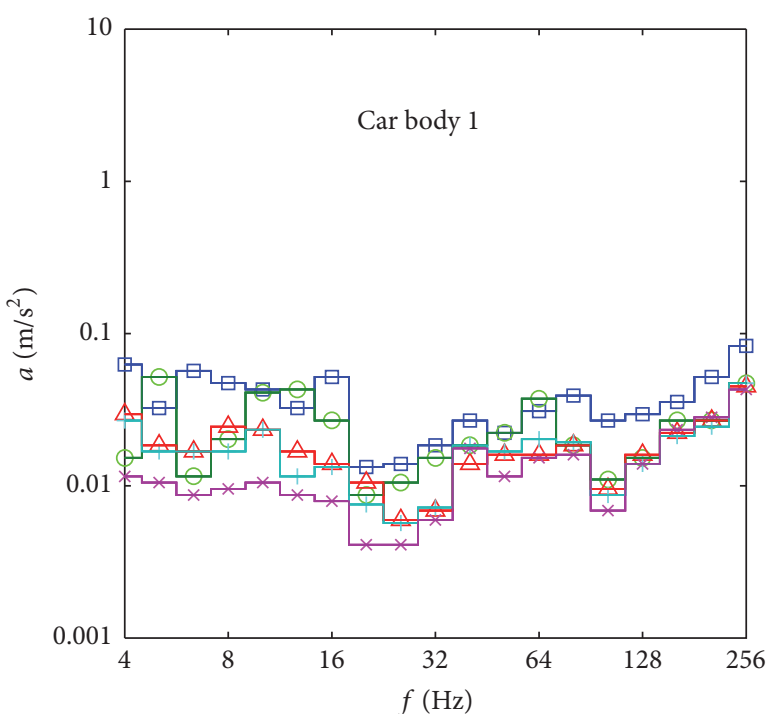

(a)

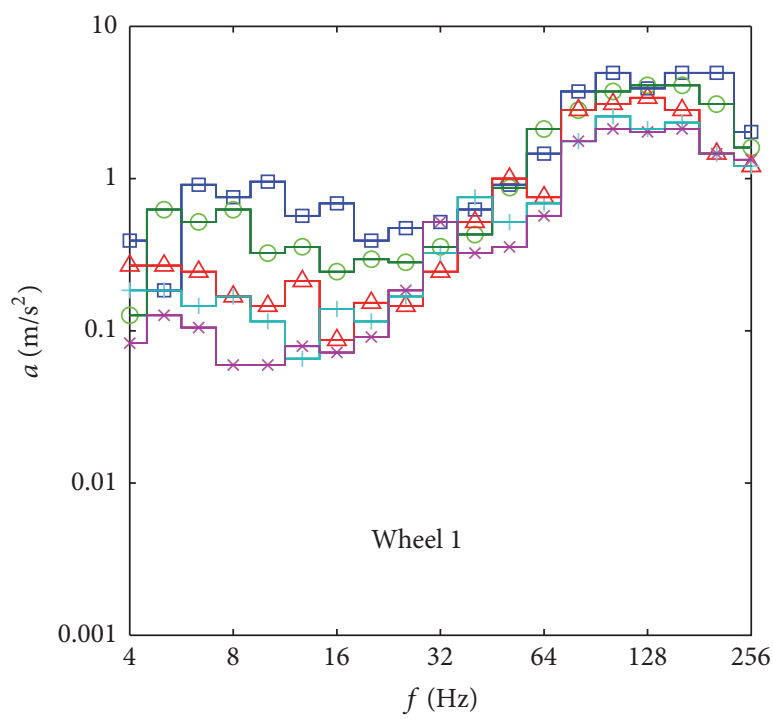

(c)

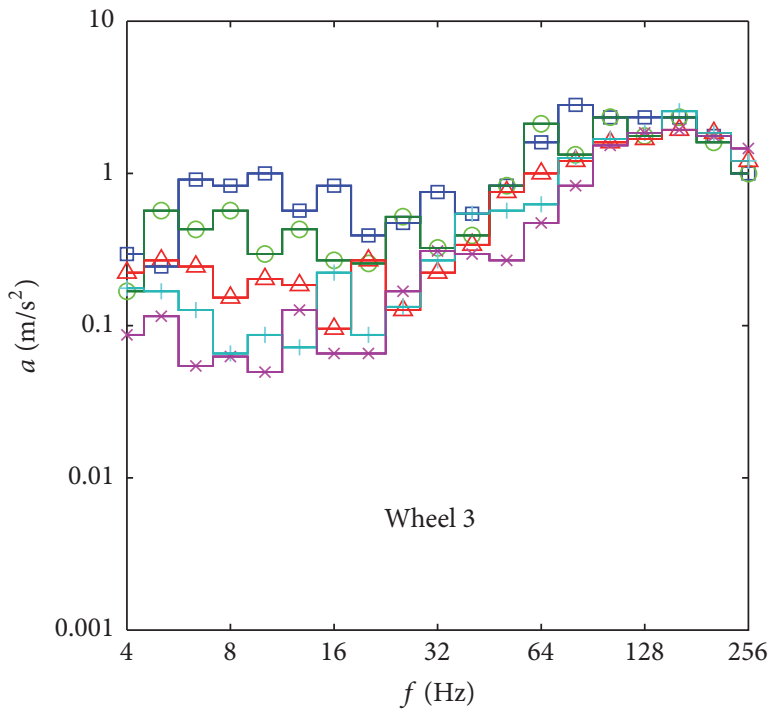

(e)

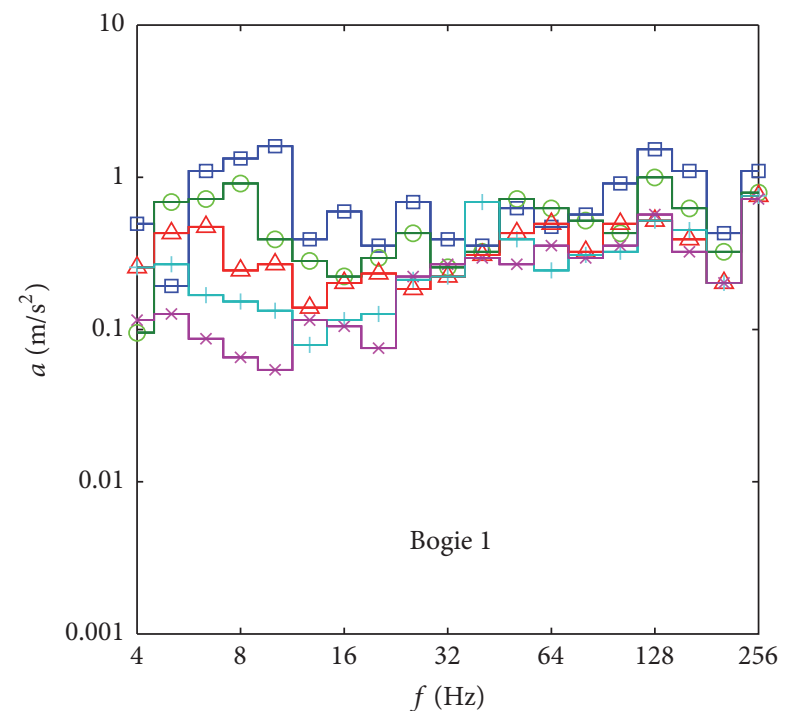

(b)

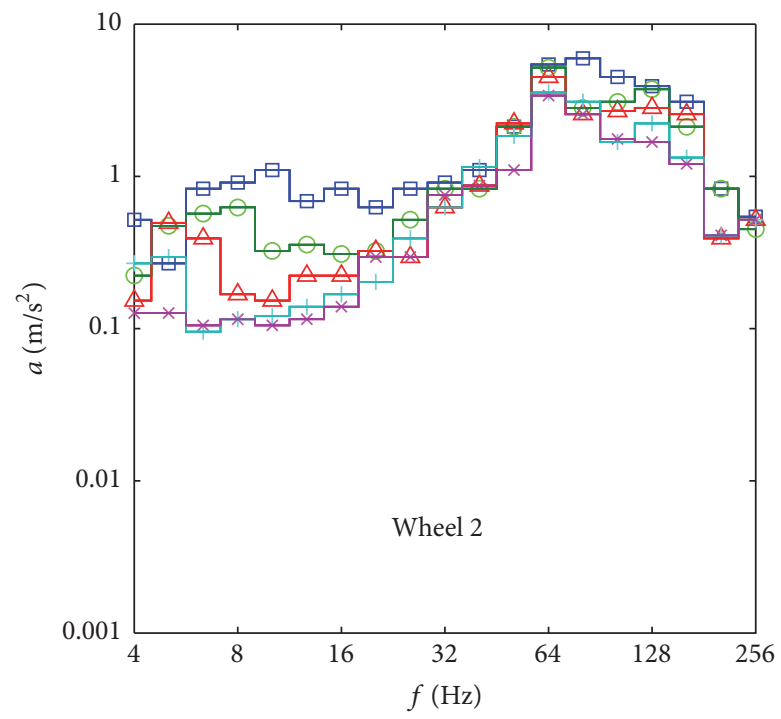

(d)

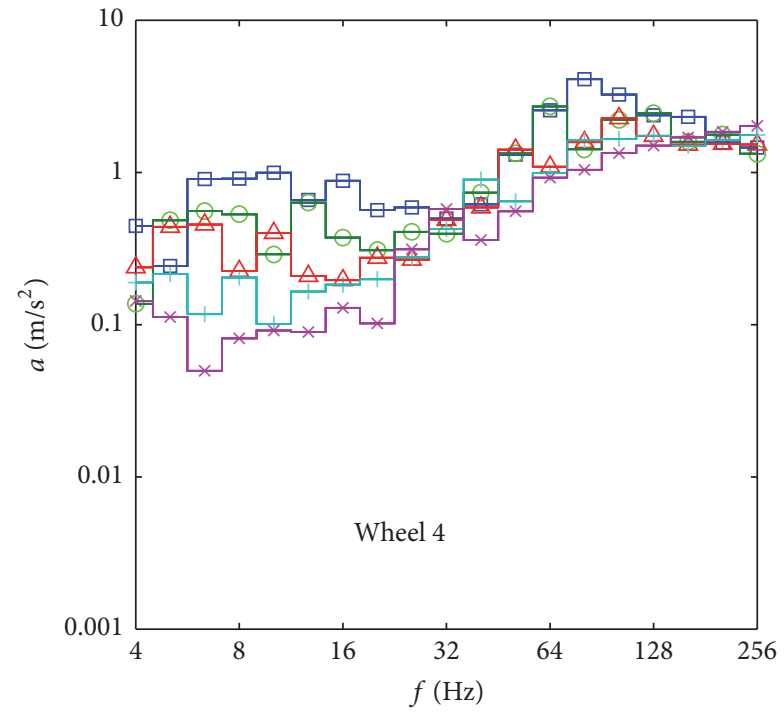

(f)

Figure 12: Continued. 


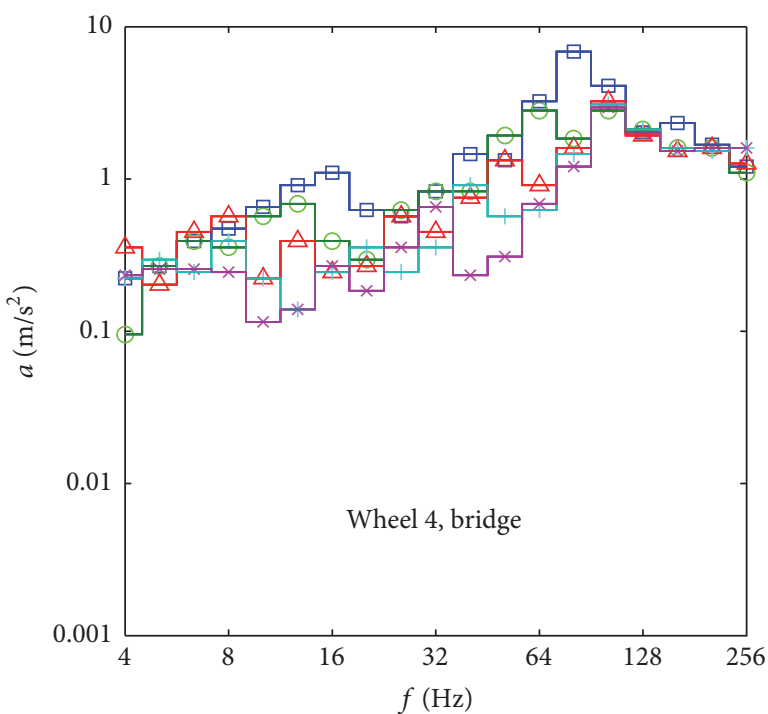

(g)

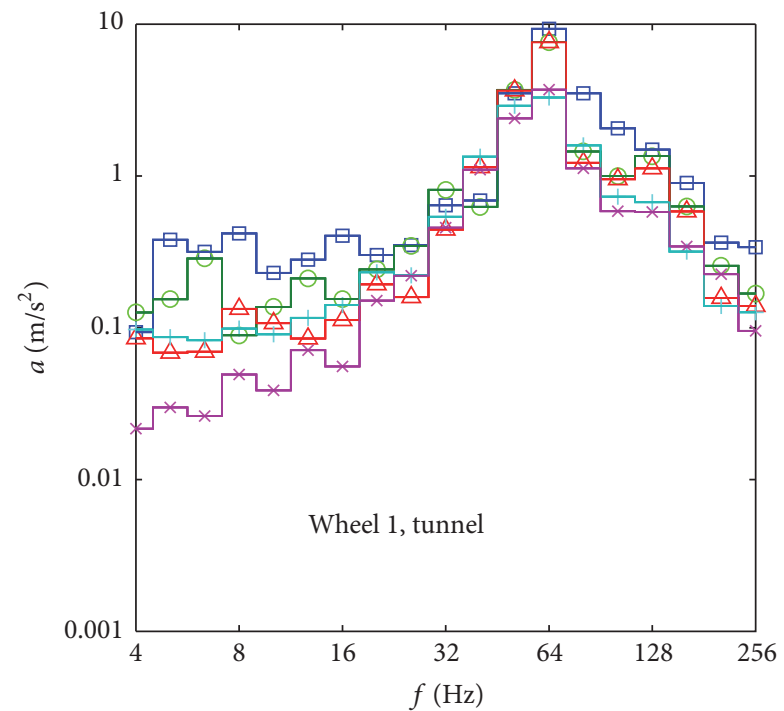

(h)

FIGURE 12: Vibrations of the railway vehicle and one-third octave band spectra for different train speeds $\square 160, \bigcirc 125, \triangle 100,+80$, and $\times$ $63 \mathrm{~km} / \mathrm{h}$, (a) car body, (b) bogie, (c) wheel 1, (d) wheel 2, (e) wheel 3, (f) wheel 4, surface line, (g) wheel 4, bridge line, and (h) wheel 1, tunnel line.

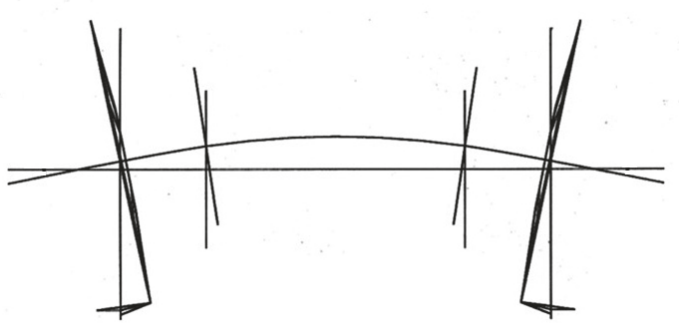

FIGURE 13: Calculated elastic mode of the wheelset on a compliant track.

first out-of-roundness of the wheels and generate dynamic loads on the track. The maxima of the wheelset and bogie acceleration, however, occur at lower frequencies than at the track and the soil. Moreover, it has been found that the dynamic loads are not strong enough to create the measured strong ground vibration at 12 and $16 \mathrm{~Hz}$. The analysis of the excitation of the midfrequency components has also considered the rigid body modes of the bogie around $10 \mathrm{~Hz}$ and the bending modes of the car body at 9 and $18 \mathrm{~Hz}$ [5], as well as the resonance of the soil layer at $12 \mathrm{~Hz}$. Theoretically, none of these resonances should have a severe influence on the ground vibration amplitudes. On the other hand, the passage of the static loads must be considered as the static loads are much higher than the dynamic loads and dominate the low- and midfrequency track vibration. As it has been proved $[3,32,36,37]$ that the regular quasi-static soil response decreases rapidly with distance to the track, it must be finally concluded that an irregular response due to random variations of the ballast and soil parameters is the reason of the higher midfrequency ground vibration which is measured at all soil measurement points $[3,8,36]$ : "The soil reaction to each impulse of a passing axle is the same for each point, if the soil is regular, but it varies if the soil has slightly differing properties at different points. Thus, in a uniform soil, the impulses at different points of excitation yield a quasi-static reaction of the soil when superposed. The superposition of the differing soil reactions in a nonuniform soil yields the mean quasi-static response but there are also irregular contributions to the soil reaction. This scattering of the axle impulses is considered as a main part of the measured train induced ground vibrations in that case" [3]. "The irregularities of the soil have been measured at this measuring site near Würzburg. The ground vibrations due to an impulse five meters left of the measuring line were compared with those due to an impulse five meters to the right. The amplitude spectra are very similar as expected for a regular soil. But if the difference of the complex transfer functions is built, a considerable portion of the impulse spectrum is left over - the scatter of the impulse" [36].

Interestingly, the bridge vibration shows also a special behavior in the midfrequency range. The different excitation of the natural modes at 7 and $11 \mathrm{~Hz}$ can also be explained by the axle-sequence spectrum. The strong reduction effect of the first minimum of the axle-sequence spectrum is most effective. Together with the second minimum and the wide maximum, the excitation of only one natural frequency, which is different for the train speeds of 100 and $160 \mathrm{~km} / \mathrm{h}$, can be explained.

The high-frequency range includes the higher orders of the wheel out-of-roundness, the rail and wheel roughness, the sleeper passage component, and the vehicle-track resonance. From the vehicle measurements at the wheelsets, it can be concluded that the wheel irregularities are more effective than the track or rail irregularities in the high-frequency range between 40 and $100 \mathrm{~Hz}$. While the wheel and track errors are random, the sleeper passage effect is a regular effect of 


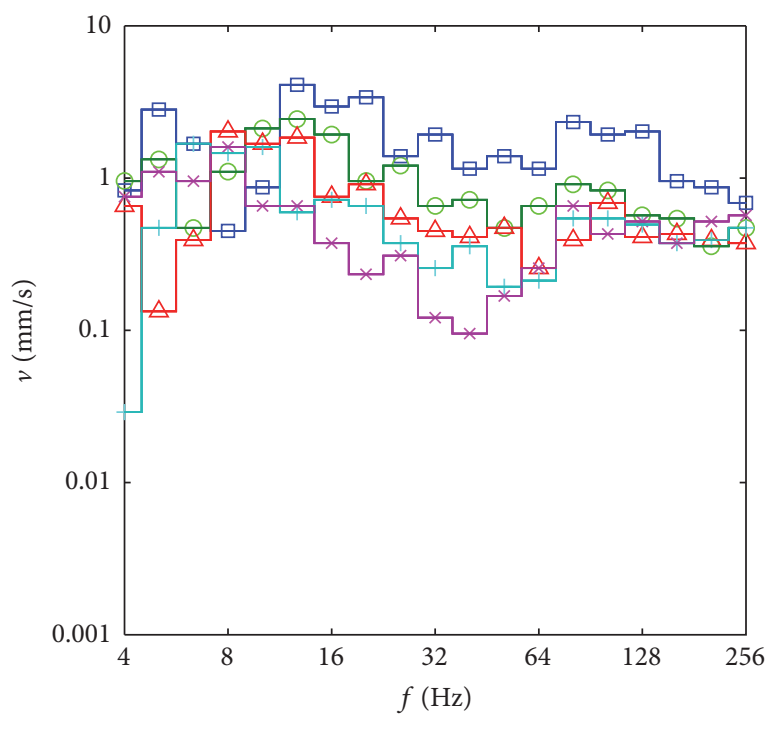

(a)

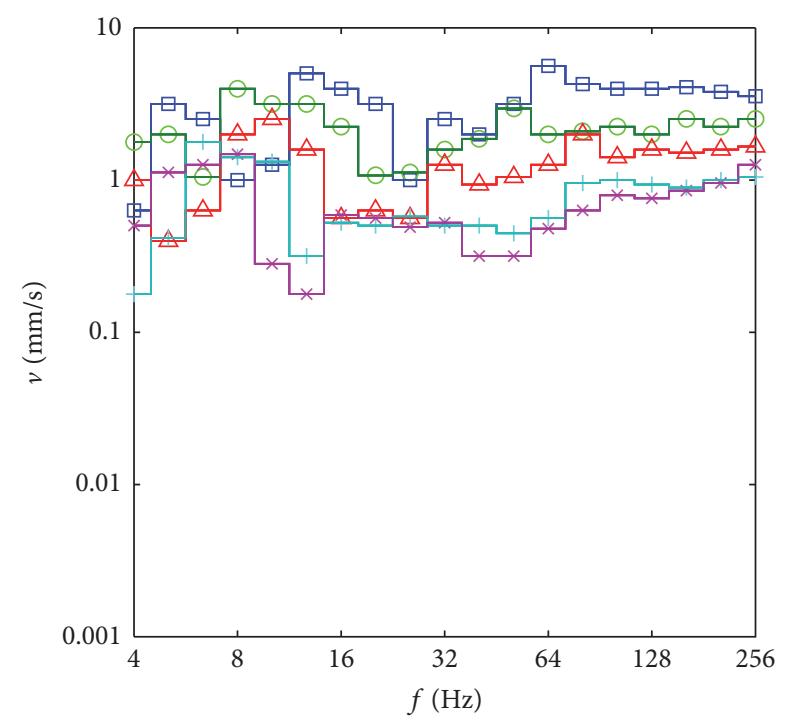

(b)

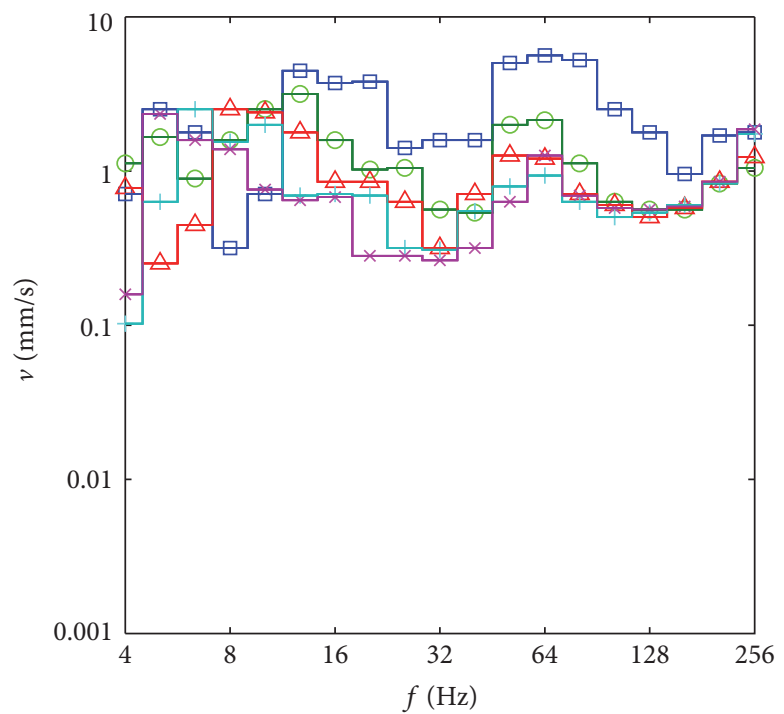

(c)

FIGURE 14: Vibrations of the rail and one-third octave band spectra for different train speeds $\square 160, \bigcirc 125, \triangle 100,+80$, and $\times 63 \mathrm{~km} / \mathrm{h},(\mathrm{a})$ surface line, (b) bridge line, and (c) tunnel line.

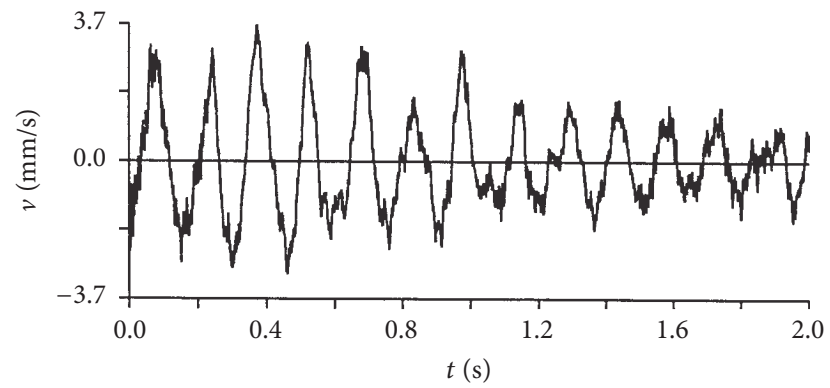

(a)

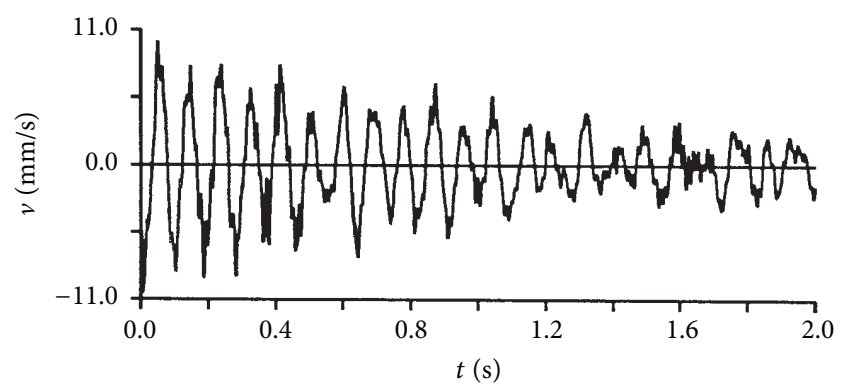

(b)

Figure 15: Vibration of the bridge and time records of the particle velocities of the $1 / 3$ point due to the train passage with (a) $100 \mathrm{~km} / \mathrm{h}$ and (b) $160 \mathrm{~km} / \mathrm{h}$. 


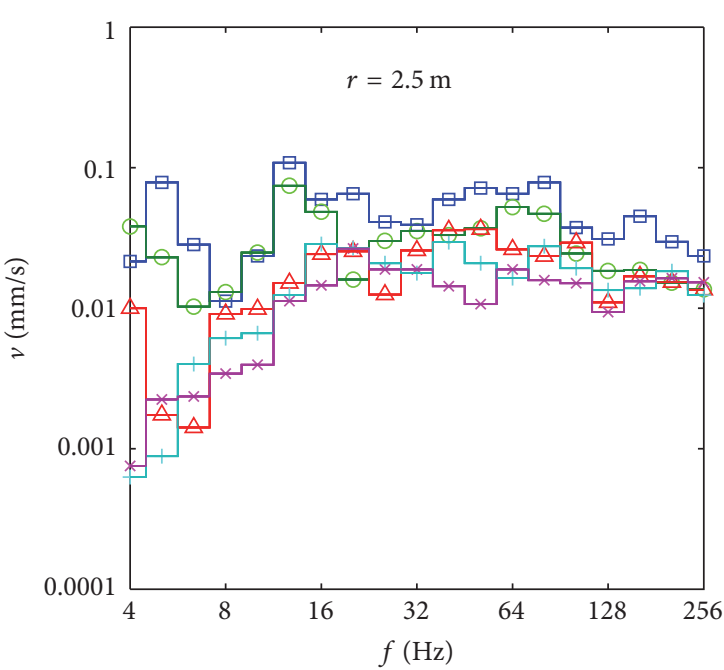

(a)

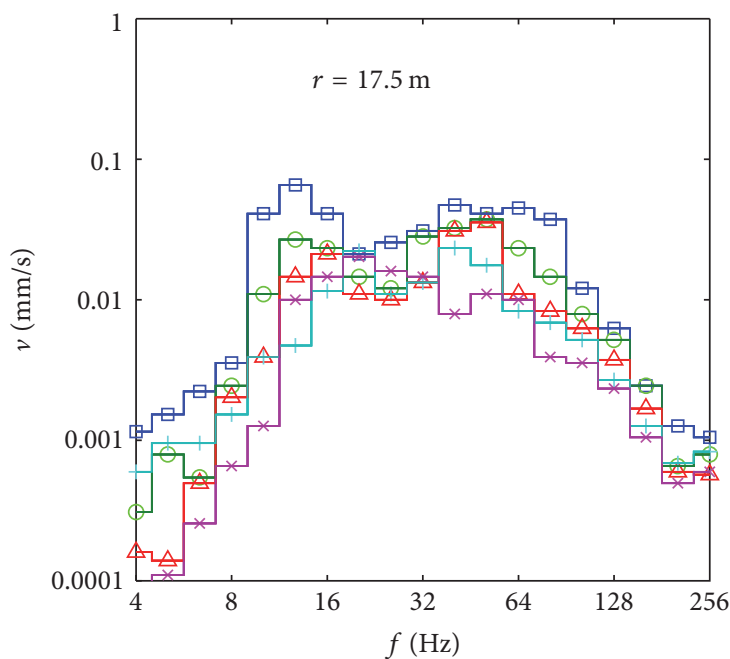

(c)

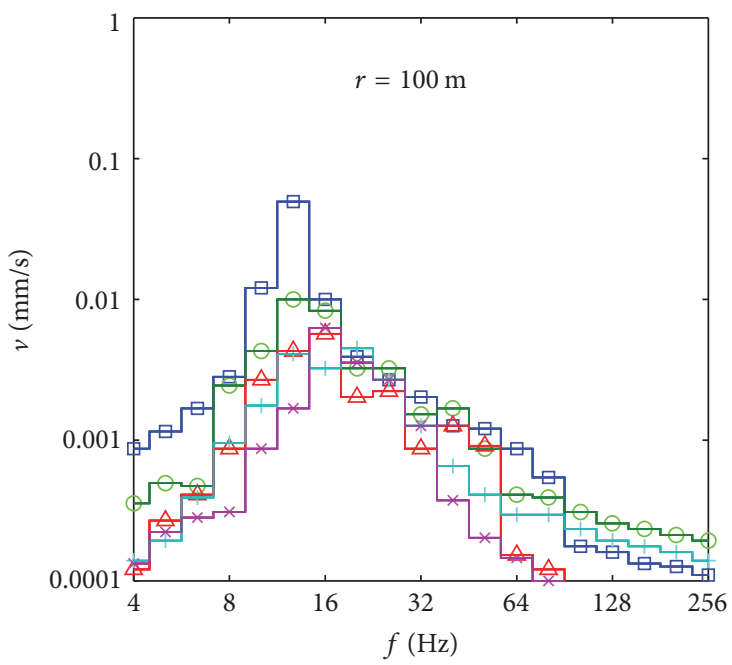

(e)

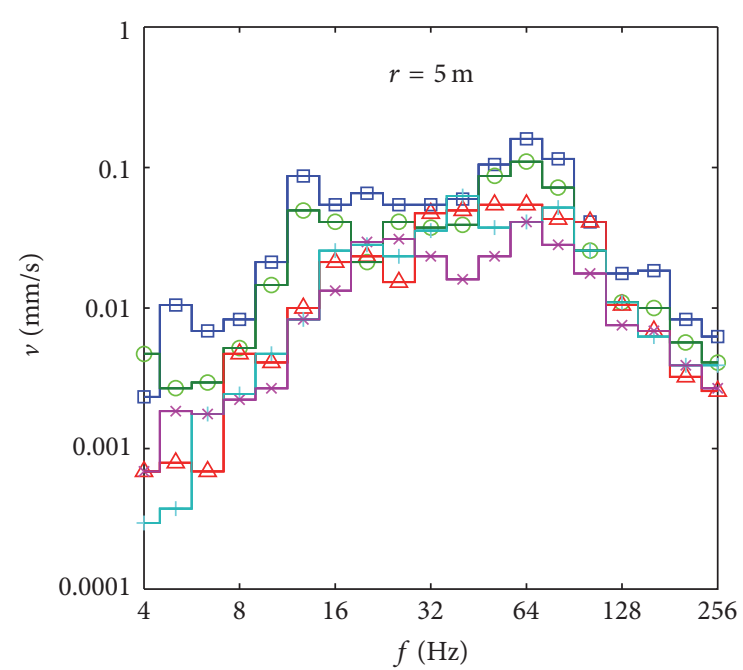

(b)

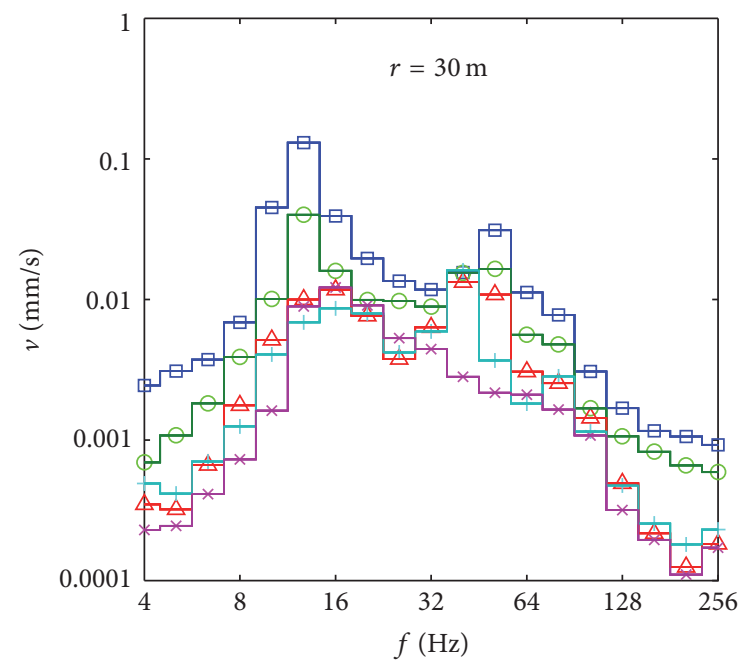

(d)

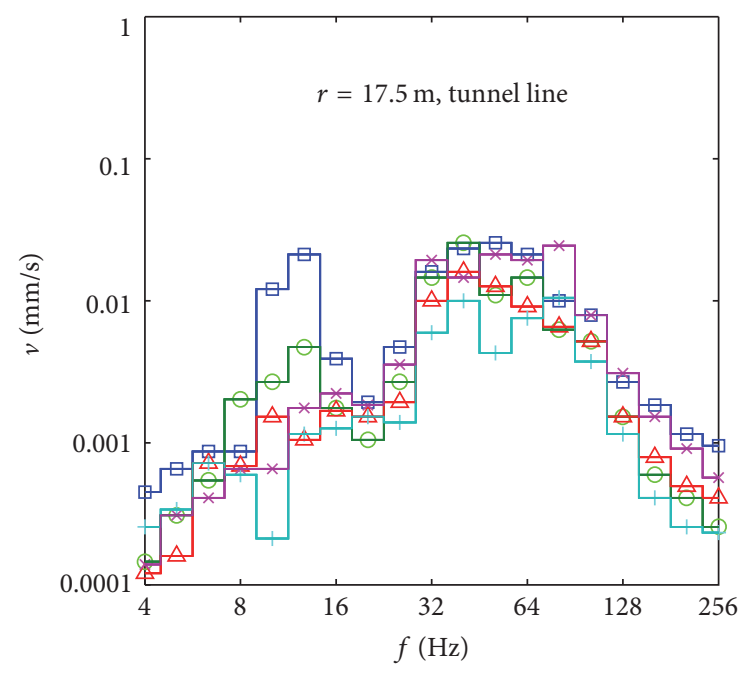

(f)

Figure 16: Vibrations of the soil and one-third octave band spectra for different train speeds $\square 160, \bigcirc 125, \triangle 100,+80$, and $\times 63 \mathrm{~km} / \mathrm{h}$, at distances (a) $2.5 \mathrm{~m}$, (b) $5 \mathrm{~m}$, (c) $17.5 \mathrm{~m}$, (d) $30 \mathrm{~m}$, (e) $100 \mathrm{~m}$, surface line, and (f) $17.5 \mathrm{~m}$ tunnel line. 
the static load and the discrete rail support on the sleepers $[3,36]$. This sleeper passage effect can be dominant in the high-frequency region. The slab track has soft rail pads and little damping so that the vehicle-track resonance becomes clearly visible. This resonance can be a rigid body resonance of the wheel on the compliant track with high dynamics forces on the track or a flexible wheel mode (see Figure 13) with limited dynamic forces [35]. The ground vibration at the slab track shows higher resonance amplitudes than the ballast track so that the stronger effect of the rigid wheelset-track mode can be assumed.

6.2. The Interaction and Relationship of the Vehicle, Track, and Soil. In general, the ground vibrations should follow the dynamic loads which have been measured by the wheelset acceleration. The track vibrations are quite different as they represent the passage of the static loads. The regular response to the static loads decreases rapidly so that the quasistatic component has no importance for the majority of the distances. The track response includes the impulse spectrum for a passing load, but also the axle-sequence spectrum for the whole train. The characteristics of the axle-sequence spectrum (two minima in an octave distance) should also be present for the sequence of the dynamic loads. Due to that, there is also a similarity between the track and the ground vibration. If the band-limited axle-impulse spectrum is found in the ground vibration, a scattered part of the axle impulses must be assumed to be generated by a random variation of the ballast and soil properties. That means that the soil is in line with the track at low frequencies due to the axle-sequence spectrum and under certain conditions to the axle-impulse spectrum. The soil vibration due to dynamic loads is always in line with the vehicle (wheelset) vibration and this can be clearly observed at the higher frequencies and at midfield distances.

\section{Conclusion}

A measuring campaign was performed including the simultaneous measurement of vehicle, track, and soil vibrations (Figures 1-3) during train runs at 16, 25, 40, 63, 80, 100, 125, $140,160 \mathrm{~km} / \mathrm{h}$ and impulse measurements at the passenger car, three track sections, and the soil. The evaluation of all these measurements has been presented and it leads to a better understanding of the excitation of railway induced ground vibration. The vibration of the vehicle and especially of the wheelset is the main source of the dynamic excitation forces. The measured acceleration of the wheelset informs about the irregularities of the track (track alignment, rail roughness) and the vehicle (wheel out-of-roundness, wheel roughness) and represents the dynamic forces which are generated by running over these irregularities. At high frequencies, the irregularities are modified according to the vehicle-track transfer function, amplified at the vehicle-track resonance, and reduced at higher frequencies. When the dynamic wheelset loads act on the railway track, they are also modified due to the characteristics of the axle sequence of the train. The axle-sequence spectrum of the train can be seen best at the track vibration, as the track is dominated by the passage of the high static loads, and it is also included in the ground vibrations. Moreover, a second important spectrum, the band-limited axle-impulse spectrum is present at the track and, in case of varying soil properties, also at the ground vibration. Finally, the spectrum of the dynamic forces is strongly modified by the transfer function of the soil. The low and high frequencies are strongly cut off due to the soil layering and damping.

All these principles are known from theory and simulation, but the experimental proof is often limited to certain aspects, for example, the axle-sequence spectra, and the quantification is left open. The simultaneous measurement of the vehicle, the track, and the soil, however, enables a unique comparison of the excitation phenomena and their modification at different measuring levels, from the vehicle and track irregularities to the vehicle acceleration and forces and further to the track response and the changing soil responses with increasing distance from the source. Particularly the simultaneous measurement of the axle-box acceleration yields a promising starting point for an excitation analysis.

The different track situations have shown different vehicle-track transfer functions, resonance frequencies, and amplifications, as well as different track irregularities. The different train speeds have shown that the coincidence of certain frequencies yields maximum amplitudes, for example, the coincidence of the sleeper-distance frequency with the vehicle-track frequency or the coincidence of the axlesequence frequency range with the layer frequency of the soil. The simultaneous measurements have shown that the train induced ground vibration highly depends on the wheelset loads generated by the irregularities, have characteristics similar to the axle-sequence and axle-impulse spectra of the track, and are strongly ruled by the characteristics of the layered and damped soil.

\section{Appendix}

\section{Linear Axle-Box Acceleration Spectra}

The linear (narrow band) spectra of the axle-box acceleration in Figure 17 clearly demonstrate the sleeper passage excitation. For each train speed $v_{T}$, there is a sharp peak at $f_{S}=v_{T} / d=v_{T} / 0.6 \mathrm{~m}$ that means at $29.2,37.0,46.3$, 57.9 , and $74.1 \mathrm{~Hz}$ for $63,80,100,125$, and $160 \mathrm{~km} / \mathrm{h}$. The acceleration amplitude strongly increases with train speed from 0.7 to $5.0 \mathrm{~m} / \mathrm{s}^{2}$, and that means that the displacement amplitude of the wheelset due to the stiffness variation on and between the sleepers is almost constant at $0.02 \mathrm{~mm}$. The linear spectra of the other wheels include more peaks around the sleeper passage frequency which are due to higher order out-of-roundness and have been evaluated in [4].

\section{Conflicts of Interest}

The author declares that there are no conflicts of interest regarding the publication of this paper. 


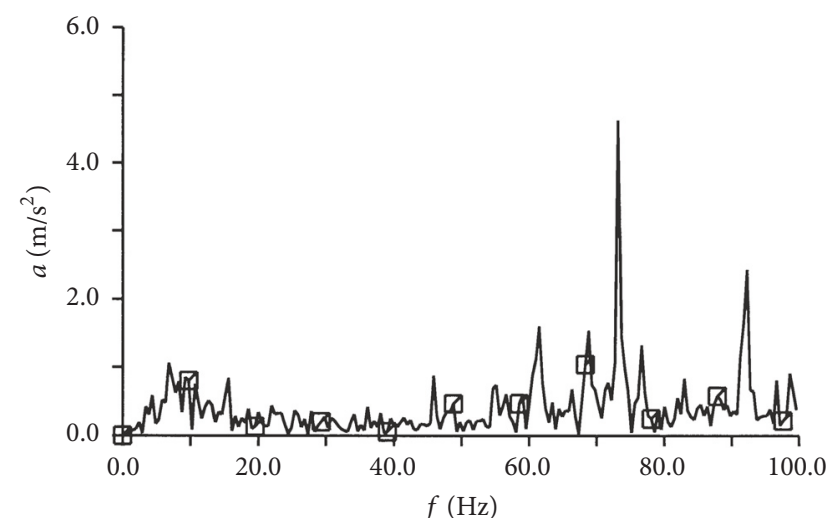

(a)

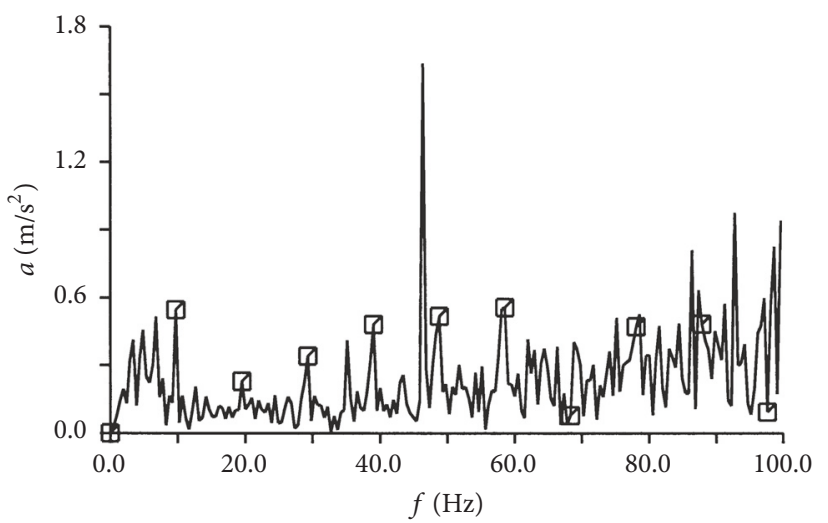

(c)

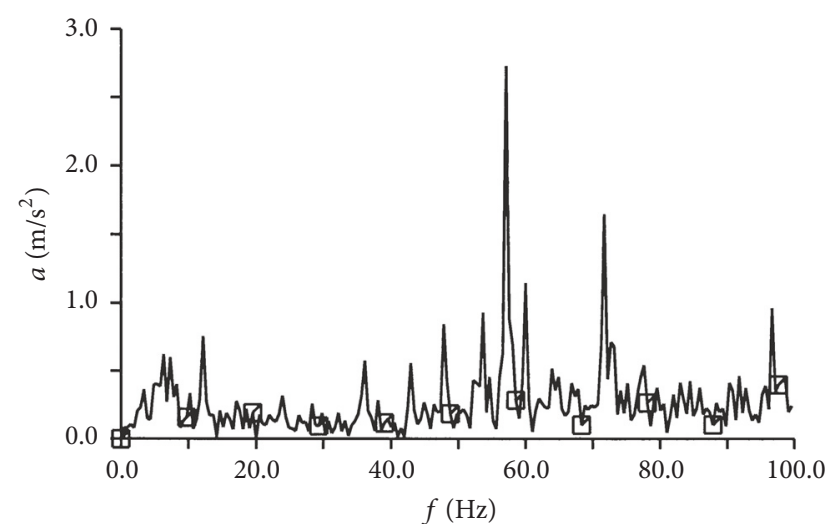

(b)

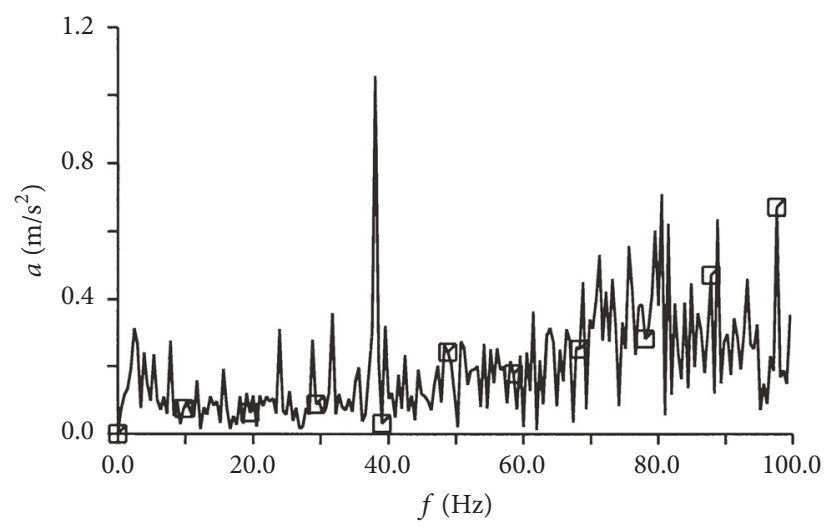

(d)

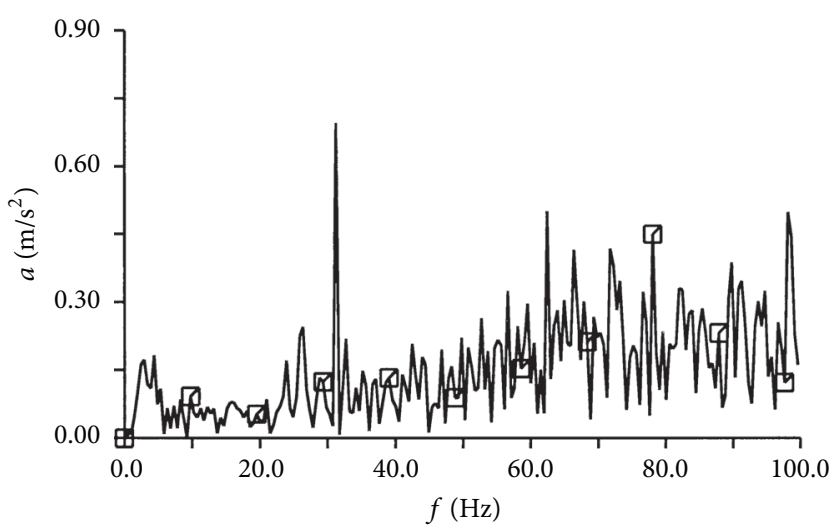

(e)

Figure 17: Linear spectra of the axle-box acceleration of wheel 4 for different train speeds (a) 160, (b) 125, (c) 100, (d) 80, and (e) 63 km/h, while passing the surface track.

\section{Acknowledgments}

The measurements have been performed by L. Auersch (surface line), S. Said (bridge line), and W. Rücker (tunnel line) and evaluated by L. Auersch and S. Said (bridge and tunnel line). The research project was directed by W. Rücker and funded by the Bundesminister für Bildung und Wissenschaft as BMBF 9346. The author would like to thank all coworkers, namely, W. Schmid (BAM) and H. Grütz (DB), for the good cooperation during the measurements.

\section{References}

[1] L. Auersch, S. Said, and W. Rücker, Das Fahrzeug-FahrwegVerhalten und die Umgebungserschütterungen bei Eisenbahnen. Forschungsbericht 243, (The vehicle-track behaviour and the environmental vibrations of railway traffic), BAM, Berlin, Germany, 2001.

[2] L. Auersch, "Dynamics of the railway track and the underlying soil: The boundary-element solution, theoretical results and their experimental verification," Vehicle System Dynamics, vol. 43, no. 9, pp. 671-695, 2005. 
[3] L. Auersch, "The excitation of ground vibration by rail traffic: Theory of vehicle-track-soil interaction and measurements on high-speed lines," Journal of Sound and Vibration, vol. 284, no. 1-2, pp. 103-132, 2005.

[4] L. Auersch, "Theoretical and experimental excitation force spectra for railway induced ground vibration - vehicle-track soil interaction, irregularities and soil measurements," Vehicle System Dynamics, vol. 48, pp. 235-261, 2010.

[5] L. Auersch, "Vehicle dynamics and dynamic excitation forces of railway induced ground vibration," in Proceedings of the 21st International Symposium on Dynamics of Vehicles on Roads and Tracks, (CD-ROM), pp. 1-12, KTH Stockholm, Stockholm, Sweden, 2009.

[6] L. Auersch, "High-speed railway tracks of a surface, bridge and tunnel line and some effects on train-induced bridge and ground vibrations," in Proceedings of the Conference on Computational Methods in Structural Dynamics and Earthquake Engineering, (CD-ROM), pp. 1-17, Corfu, Greece, 2011.

[7] G. Hölzl and G. Fischer, "Körperschall bzw. Erschütterungsausbreitung an oberirdischen Schienenverkehrswegen," Eisenbahntechnische Rundschau, vol. 34, (Propagation of ground vibration near surface railway lines), pp. 469-477, 1985.

[8] G. Huber, Erschütterungsausbreitung beim Rad/Schiene-System [Thesis], University Karlsruhe, Karlsruhe, Germany, 1988, (Propagation of ground vibration due to the wheel/rail system).

[9] M. Heckl, G. Hauck, and R. Wettschureck, "Structure-borne sound and vibration from rail traffic," Journal of Sound and Vibration, vol. 193, no. 1, pp. 175-184, 1996.

[10] M. Bahrekazemi, Train-induced ground vibration and its prediction [Thesis], KTH Stockholm, Stockholm, Sweden, 2004.

[11] W. Zhai, K. Wei, X. Song, and M. Shao, "Experimental investigation into ground vibrations induced by very high speed trains on a non-ballasted track," Soil Dynamics and Earthquake Engineering, vol. 72, pp. 24-36, 2015.

[12] G. Degrande and L. Schillemans, "Free field vibrations during the passage of a thalys high-speed train at variable speed," Journal of Sound and Vibration, vol. 247, no. 1, pp. 131-144, 2001.

[13] P. Galvin, Analisis numerico y experimental de las vibraciones ocasionadas por el paso de trenes de alta velocidad en el suelo y en structuras cercana a la via [Thesis], University of Sevilla, 2007, (Numerical and experimental analysis of the vibrations at high speed railway lines in the soil and in adjacent structures).

[14] P. Galvín and J. Domínguez, "Experimental and numerical analyses of vibrations induced by high-speed trains on the CórdobaMálaga line," Soil Dynamics and Earthquake Engineering, vol. 29, no. 4, pp. 641-657, 2009.

[15] G. Kouroussis, Modélisation des effets vibratoirs du traffic ferroviaire sur l'environnement [Thèse de doctorat], Université de Mons, Mons, Belgium, 2009, (Modelling of the vibratory effects of railway traffic on the environment).

[16] G. Kouroussis, O. Verlinden, and C. Conti, "Free field vibrations caused by high-speed lines: measurements and time domain simulation," Soil Dynamics and Earthquake Engineering, vol. 31, pp. 692-707, 2011.

[17] A. Romero, Predicción, medida experimental y evaluación de las vibraciones producidas por el tráfico ferroviario [Thesis], University of Sevilla, Sevilla, Spain, 2012, (Prediction, measurement and evaluation of the vibrations produced by the railway traffic).

[18] P. Galvín, A. Romero, and J. Domínguez, "Fully three-dimensional analysis of high-speed train-track-soil-structure dynamic interaction," Journal of Sound and Vibration, vol. 329, pp. 5147-5163, 2010.
[19] D. Connolly, Ground Borne Vibrations from High-Speed Trains [Thesis], University of Edinburgh, 2013.

[20] M. Maldonado, Vibrations dues au passage d'un tramwaymesures experimentales et simulations numériques [Thesis], Ecole Centrale, Nantes, France, 2009, (Vibrations due to the passage of a tram-measurements and numerical simulations).

[21] P. Alves Costa, Vibrações do sistema via-maciço induzidas por tráfego ferroviário-modelação numérica e validação experimental [Thesis], University of Porto, Portugal, 2011, (Vibrations of the track-soil system induced by railway traffic - numerical modelling and experimental validation).

[22] P. Alves Costa, R. Calçada, and A. Silva Cardoso, “Track-ground vibrations induced by railway traffic: in-situ measurements and validation of a 2.5D FEM-BEM model," Soil Dynamics and Earthquake Engineering, vol. 32, no. 1, pp. 111-128, 2012.

[23] N. Triepaischajonsak, The influence of various excitation mechanisms on ground vibration from trains [Thesis], University Southampton, Southampton, UK, 2012.

[24] N. Triepaischajonsak, D. Thompson, C. Jones, J. Ryue, and J. Priest, "Ground vibration from trains: experimental parameter characterisation and validation of a numerical model," Journal of Rail and Rapid Transport, vol. 225, pp. 140-153, 2011.

[25] J. Nielsen, Train/track interaction-coupling of moving and stationary dynamic systems-theoretical and experimental analysis of railway structures considering wheel and track imperfections [Thesis], Chalmers University, Gothenburg, Sweden, 1993.

[26] R. Fröhling, Deterioration of railway track due to dynamic vehicle loading and spatially varying track stiffness [Thesis], University of Pretoria, Pretoria, South Africa, 1997.

[27] C. Esveld, MRT production, Delft, 2nd edition, 2011.

[28] L. Auersch and M. Maldonado, "Interaction véhicule-voie-sol et vibrations dues aux trains - Modélisation et vérifications expérimentales," Revue Européenne De Mécanique Numérique, vol. 20, no. 5-6, pp. 257-280, 2011, (Vehicle-track-soil interaction and vibrations due to trains - modelling and experimental verification).

[29] H. Kuppelwieser and A. Ziegler, "A tool for predicting vibration and structure-borne noise immissions caused by railways," Journal of Sound and Vibration, vol. 193, no. 1, pp. 261-267, 1996.

[30] J. Nelson and H. Saurenman, "A prediction procedure for rail transportation groundbourne noise and vibration," Transportation Research Record, no. 1143, pp. 26-35, 1987.

[31] C. Hanson, D. Towers, and L. Meister, "Transit noise and vibration impact assessment," Report FTA-VA-90-1003-06 for the Federal Transit Administration, HMMH Inc., Burlington, 2006.

[32] G. Lombaert and G. Degrande, "Ground-borne vibration due to static and dynamic axle loads of InterCity and high-speed trains," Journal of Sound and Vibration, vol. 319, no. 3-5, pp. 1036-1066, 2009.

[33] G. Kouroussis, D. P. Connolly, K. Vogiatzis, and O. Verlinden, "Modelling the environmental effects of railway vibrations from different types of rolling stock: a numerical study," Shock and Vibration, vol. 2015, Article ID 142807, 15 pages, 2015.

[34] H. Zakel and L. Willenbrink, "Körperschallmessungen an einem bm 235-wagen bei der fahrt auf verschiedenen oberbauten der neubaustrecke fulda-würzburg," Report to BAM, Deutsche Bahn AG Forschungs- und Technologiezentrum, München, Germany, 1997, (Measurement of the vibration of a $\mathrm{Bm} 235$ passsenger car during the test runs on different tracks at the high-speed line Fulda-Würzburg). 
[35] H. Ulrich, M. Weiland, C. Schedlinski, and M. Link, "Experimen-telle modalanalyse an einem schnellzugwagen der deutschen bahn AG," Report to BAM, Universität Kassel, Kassel, Germany, 1994, (Experimental modal analysis at a passenger car of the German Railway).

[36] L. Auersch, "Ground vibration due to railway traffic-the calculation of the effects of moving static loads and their experimental verification," Journal of Sound and Vibration, vol. 293, no. 3-5, pp. 599-610, 2006.

[37] X. Sheng, C. Jones, and D. Thompson, "Comparison of a theoretical model for quasi-statically and dynamically induced environmental vibration from trains with measurements," Journal of Sound and Vibration, vol. 267, no. 3, pp. 621-635, 2003. 


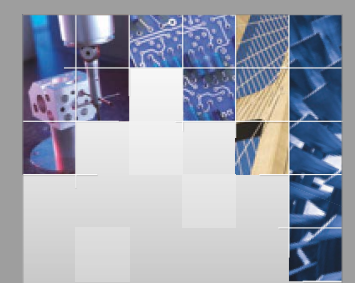

\section{Enfincering}
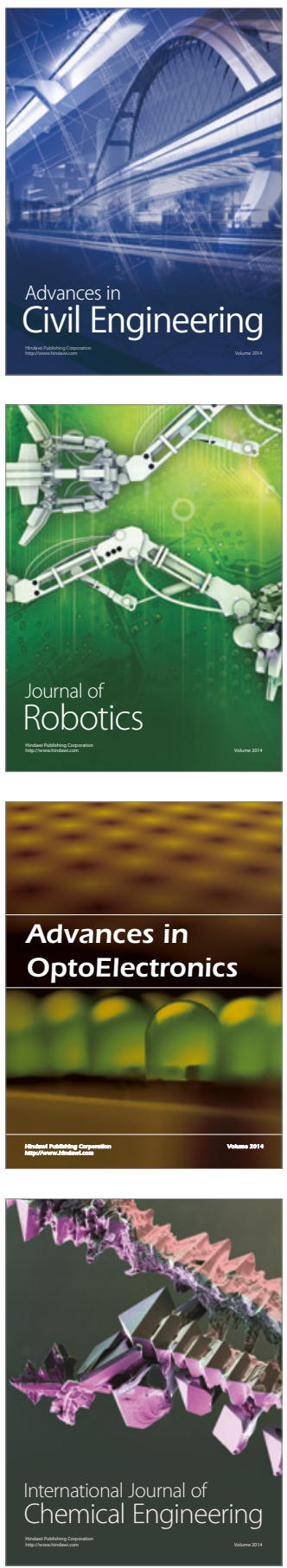

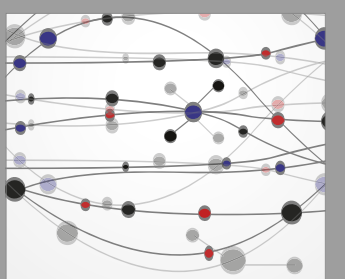

The Scientific World Journal

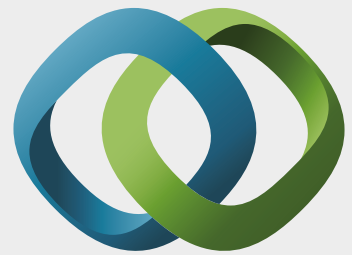

\section{Hindawi}

Submit your manuscripts at

https://www.hindawi.com
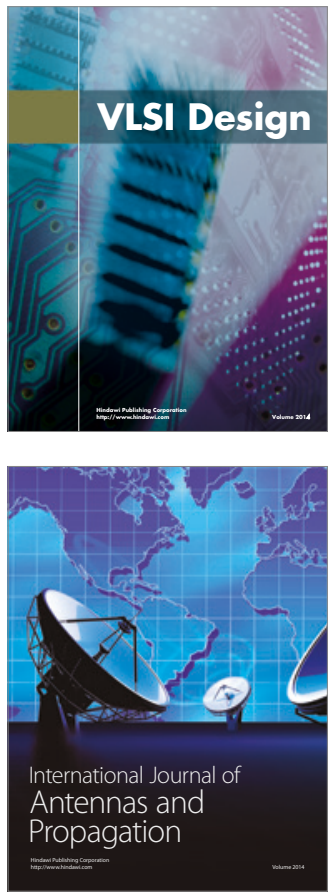

\section{Rotating}

Machinery
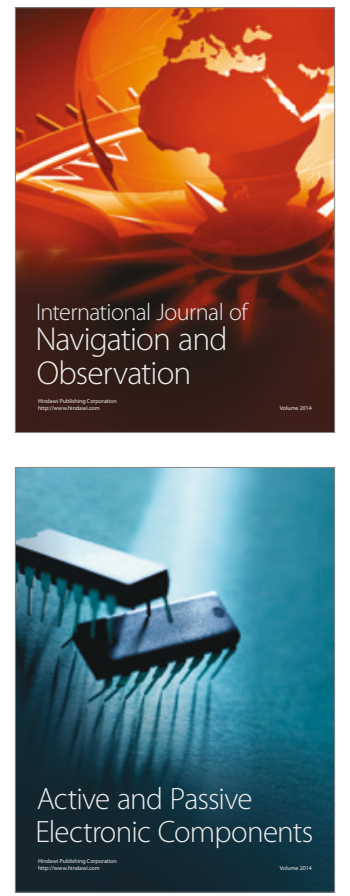
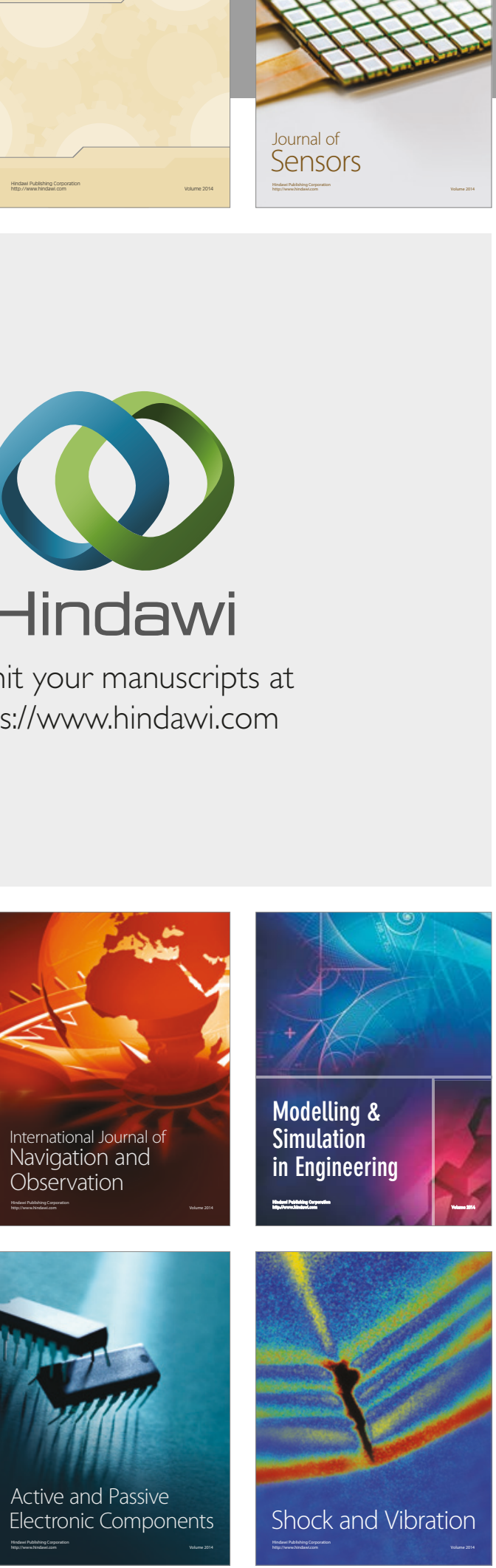
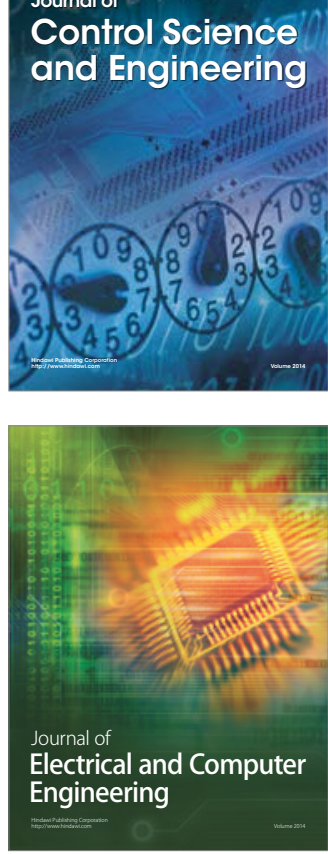

Distributed

Journal of

Control Science

and Engineering
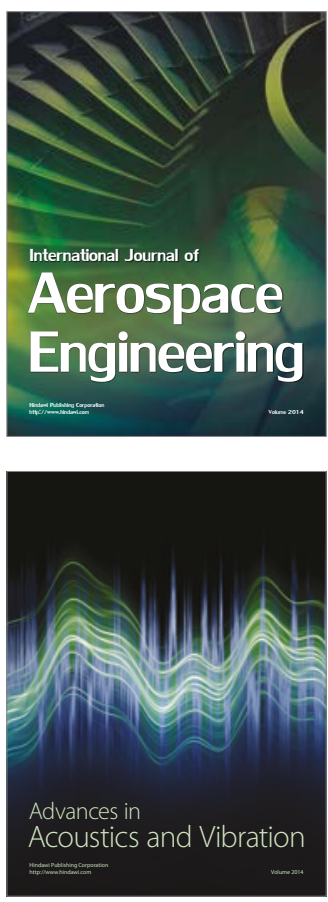

Sensor Networks 